This is a preprint of a article accepted by Polymer and is subject to Elsevier Copyright. The final version will be available at https://doi.org/10.1016/j.polymer.2019.02.001

\title{
Flexible aromatic disulfide monomers for high-performance self- healable linear and cross-linked poly(urethane-urea) coatings
}

\author{
Sil Nevejans, ${ }^{a, b}$ Nicholas Ballard, ${ }^{a}$ Mercedes Fernández, ${ }^{a}$ Bernd Reck, ${ }^{b}$ and José M. Asua ${ }^{a^{*}}$ \\ aPOLYMAT, University of the Basque Country UPV/EHU, Joxe Mari Korta Center, Avenida Tolosa \\ 72, 20018 Donostia-San Sebastián, Spain, E-mail: jm.asua@ehu.es \\ ${ }^{b}$ Dispersions and Colloidal Materials, BASF SE, 67056 Ludwigshafen, Germany
}

\begin{abstract}
Implementation of the self-healing concept in coatings is challenging because they have to combine mechanical strength and chain mobility. This challenge is addressed in this work by studying the effect of the polymer microstructure on the mechanical properties and selfhealing ability of waterborne poly(urethane-urea) coatings containing aromatic disulfide dynamic bonds. The structural modifications studied are the concentration and flexibility of the aromatic disulfide units and the effect of cross-linking. The effects and limits of these structural changes on the mechanical properties of the polymers and their healability were determined via a combination of DMA measurements, tensile tests, and rheological and scratch closure experiments. It was found that the flexibility of the disulfide unit was key to develop more efficient self-healing materials which offer the necessary molecular mobility for self-healing while simultaneously maintaining a level of mechanical strength that are attractive for coating applications.
\end{abstract}

Keywords: coatings, poly(urethane-urea), waterborne dispersion, self-healing, aromatic disulfide, mechanical strength

\section{Introduction}

In order to improve the lifespan of polymer materials, intrinsically healing polymers have been developed that incorporate various dynamic functional groups into the polymer and allow for recovery of the material following damage as a result of bond rearrangement.[19] Often, this research is focused on the quantity and type of dynamic bonds and supramolecular interactions that are introduced into the material with the aim to increase the self-healing ability of the material. However, it is important to emphasize that next to the obvious influence of the reversible chemistries involved in self-healing, the conditions imposed by the applications cannot be underestimated. This is particularly relevant in the case of coatings, where damages leave the substrate unprotected against the initiation and rapid propagation of corrosion processes. On the one hand, coatings require high strength at the service temperature to provide this damage resistance and minimize dirt pickup which typically restricts the molecular mobility and thus limits the potential for bond exchange and self-healing, while on the other hand, mobility is necessary for healing. Therefore, the challenge for healable coatings is to develop a polymer with such a microstructure that it is mechanically strong at the service temperature and undergoes a 
conformational change upon exposure to external stimuli, such as heat, so that it becomes mobile enough to allow scratch closure and bond exchange. Furthermore, since the coating market is shifting from solvent-based to waterborne coatings, because of environmental concerns and governmental regulations, the challenge is further enlarged. Additionally, the polymer should thus be synthesized in an aqueous dispersed system where the coating is the result of coalescence of individual particles after water evaporation.

Plenty of research regarding self-healing polymers has focused on polyurethane(-urea)s $\mathrm{PU}(\mathrm{U}),[10-17]$ because these polymers are often used in high-end applications, provide some intrinsic self-healing characteristics since dynamic hydrogen bonds can be formed between their backbones and offer a very flexible synthesis which makes it relatively easy to incorporate dynamic covalent bonds, such as disulfides, into the backbone.[18-22] However, the analysis of these works shows that the ultimate goal of developing mechanically strong self-healable polymers is difficult to reach. To best of our knowledge, the strongest $\mathrm{PU}(\mathrm{U})$ elastomers based on aromatic disulfides described in literature so far are those developed by Kim et al. and Yang et al.,[23,24] showing stress-strain curves without yield point and reaching a tensile strength at fracture of $6.8 \mathrm{MPa}$ (strain rate of $100 \mathrm{~mm} \cdot \mathrm{min}^{-1}$ ) and $7.7 \mathrm{MPa}$ (cross-head speed of $500 \mathrm{~mm} \cdot \mathrm{min}^{-1}$ ) respectively. However, these materials are not suitable for coatings, because they present a low Young's modulus and even their tensile strength does not meet the requirements of commercial coatings.[25-29] Similar problems can be found when investigating the research done on waterborne $\mathrm{PU}(\mathrm{U}) \mathrm{s}$. For example, films cast from polyurethane aqueous dispersions containing sulphonate groups could be healed at $100^{\circ} \mathrm{C}$, but the Young's modulus was low and the maximum tensile strength was roughly $8 \mathrm{MPa}$ (strain rate not disclosed).[30] Alternatively, coumarin containing waterborne polyurethanes could be healed at room temperature when exposed to UV irradiation at $254 \mathrm{~nm}$, but presented tensile strengths lower than $2 \mathrm{MPa}$ (cross-head speed of $20 \mathrm{~mm} \cdot \mathrm{min}^{-1}$ ).[31] Also waterborne hybrids containing alkoxysilane and aromatic disulfide moieties showed self-healing at room temperature, while tensile strengths up to $4.5 \mathrm{MPa}$ (strain rate of $20 \mathrm{~mm} \cdot \mathrm{min}^{-1}$ ) could be obtained.[32] Recently, Wan and Chen have reported waterborne linear PUUs containing aliphatic disulfide bonds in the polymer backbone that show healing abilities at $65^{\circ} \mathrm{C}$,[33] and interesting mechanical properties (a tensile strength of $18 \mathrm{MPa}$ at a cross-head speed of $200 \mathrm{~mm} \cdot \mathrm{min}^{-1}$ ) that were enhanced by incorporating graphene oxide.[34]

As cross-linked polymers have a high mechanical strength and even thermoset polymers containing dynamic bonds can be reprocessed,[35-37] they may be an interesting alternative for healable coatings. Moreover, the impact of the cross-linking density on the ability of a polymer to heal has been the focus of several recent studies.[38-41] For example, García and co-workers recently described the effect of the polymer structure of a self-healing PUU on the viscoelastic and interfacial healing behaviour by performing rheological measurements and fracture mechanical tests and correlating them to healing tests.[42] They produced polymeric networks with different cross-linking densities, while retaining the same amount of reversible bonds through the introduction of an aromatic 
disulfide compound. Although the polymers containing lower cross-linking densities showed high viscoelastic and healing properties, only low tensile strength could be obtained in that case, showing that finding a good balance between mechanical properties and a high healing ability is not straightforward.

This work focuses on waterborne poly(urethane-urea) dispersions containing aromatic disulfide moieties in which the effect of the polymer microstructure/architecture on mechanical properties and self-healing ability of the PUU is investigated. The structural modifications studied here are the concentration and flexibility of the aromatic disulfide units and the effect of cross-linking. More specifically, two disulfide compounds, $\mathrm{S}_{2}\left(\mathrm{Ph}\left(\mathrm{CH}_{2}\right)_{3} \mathrm{OH}\right)_{2}(\mathrm{~S} 3)$ and the more flexible alternative $\mathrm{S}_{2}\left(\mathrm{Ph}\left(\mathrm{CH}_{2}\right)_{6} \mathrm{OH}\right)_{2}$ (S6) were synthesized and incorporated into the PUU backbone. Linear polymers were obtained using a bifuntional chain extender (hexane-1,6-diamine, HDA) and trifunctional chain extenders (diethylenetriamine, DETA) were used to form polymer networks. The effects and limits of these structural changes on the mechanical properties of the polymers and their healability were determined via a combination of DMA measurements, tensile tests, and rheological and scratch closure experiments.

\section{Experimental}

\section{Materials}

Bis(4-hydroxyphenyl)disulfide $\quad\left(\mathrm{S}_{2}(\mathrm{PhOH})_{2}, \quad\right.$ Enamine, 95\%), 2,2-bis(hydroxymethyl)propionic acid (DMPA, GEO specialty chemicals, >96\%), 3-bromo-1-propanol (Apollo Scientific, 96\%), 6-bromo-1-propanol (Apollo Scientific, 96\%), dibutylamine $0.1 \mathrm{~N}$ in xylol (DBA, Bernd Kraft), dibutyltin dilaurate (DBTL, TCl, >95\%), ethyl acetate (EtOAc, Brenntag, >98\%), diethylene triamine (DETA, Merck KGaA, $\geq 98 \%$ ), hexane-1,6-diamine (HDA, Sigma-Aldrich, 98\%), hexane (Brenntag, 100\%), hydrochloric acid $1 \mathrm{~N}$ in water ( $\mathrm{HCl}$, Bernd Kraft), isophorone diisocyanate (IPDI, Bayer Material Science, >99\%), Nmethylpyrrolidon (NMP, Honeywell, $\geq 99.9 \%$ ), methyl ethyl ketone (MEK, Honeywell, $\geq 99.5 \%$ ), polytetrahydrofuran (PolyTHF, BASF, $2000 \mathrm{~g} \cdot \mathrm{mol}^{-1}$ ), potassium carbonate $\left(\mathrm{K}_{2} \mathrm{CO}_{3}\right.$, Sigma-Aldrich, $\geq 99 \%$ ), sodium chloride ( $\mathrm{NaCl}$, Sigma-Aldrich, $\left.\geq 99.5 \%\right)$, sodium sulfate $\left(\mathrm{Na}_{2} \mathrm{SO}_{4}\right.$, Honeywell, $\geq 99 \%$ ), tetrahydrofuran (THF, Scharlab), triethylamine (TEA, Sigma-Aldrich, $\geq 99 \%$ ) were used as received.

\section{Synthesis of modified aromatic disulfide compounds}

In order to obtain bis[4-(6'-hydroxyhexoxy)phenyl]disulfide $\left(\mathrm{S}_{2}\left(\mathrm{Ph}\left(\mathrm{CH}_{2}\right)_{3} \mathrm{OH}\right)_{2}\right.$ or $\left.\mathrm{S} 3\right)$ (Figure 1), a mixture of bis(4-hydroxyphenyl)disulfide (100 g, $0.40 \mathrm{~mol}$ ), 3-bromo-1propanol $(51 \mathrm{~mL}, 1.00 \mathrm{~mol})$ and potassium carbonate $(554 \mathrm{~g}, 4.01 \mathrm{~mol})$ was stirred at $60^{\circ} \mathrm{C}$ for $48 \mathrm{~h}$ in THF (100 wt\% of the solid reagents) as solvent, as inspired by a synthetic method reported by Otsuka and co-workers.[43] Similarly, an alternative aromatic disulfide compound with longer alkyl chain, bis[4-(6'-hydroxyhexoxy)phenyl]disulfide $\left(\mathrm{S}_{2}\left(\mathrm{Ph}\left(\mathrm{CH}_{2}\right)_{6} \mathrm{OH}\right)_{2}\right.$ or S6) (Figure 1), was synthesized by mixing bis $(4-$ 
hydroxyphenyl)disulfide (53.5 g, $0.21 \mathrm{~mol}), 6$-bromo-1-hexanol $(68.6 \mathrm{~mL}, 0.52 \mathrm{~mol})$, potassium carbonate $(290.0 \mathrm{~g}, 2.10 \mathrm{~mol})$ in THF (120 wt\% of solid reagents) as solvent for $120 \mathrm{~h}$ at $60^{\circ} \mathrm{C}$. Both of the reactions were carried out under $\mathrm{N}_{2}$-atmosphere in a jacketed glass reactor equipped with a mechanical stirrer and a condenser. Afterwards, the reaction mixtures were filtered and washed with EtOAc. The obtained organic filtrates were washed with $1 \mathrm{~N} \mathrm{HCl}$ and brine, after which they were dried over anhydrous $\mathrm{Na}_{2} \mathrm{SO}_{4}$. The solvent was removed from the products under vacuum and the residue materials were purified by recrystallization in an EtOAc:Hexane-mixture (3:5). Finally, the products were dried at $50^{\circ} \mathrm{C}$ under vacuum to give bis[4-(3'-hydroxypropyloxy)phenyl]disulfide $\mathrm{S}_{2}\left(\mathrm{Ph}\left(\mathrm{CH}_{2}\right)_{3} \mathrm{OH}\right)_{2}$ (S3) and bis[4-(6'-hydroxyhexoxy)phenyl]disulfide $\mathrm{S}_{2}\left(\mathrm{Ph}\left(\mathrm{CH}_{2}\right)_{6} \mathrm{OH}\right)_{2}$ (S6), respectively. [IUPAC: ((disulfanediylbis(4,1-phenylene))bis(oxy))bis(propan-1-ol) and 6,6'((disulfanediylbis(4,1-phenylene))bis(oxy))bis(hexan-1-ol), respectively].

$\mathrm{S}_{2}\left(\mathrm{Ph}\left(\mathrm{CH}_{2}\right)_{3} \mathrm{OH}\right)_{2}$ (S3). Yield: $70.5 \mathrm{~g}$ (64 mol\%). Pale yellow powder. FTIR (neat, $\left.\mathrm{cm}^{-1}\right)$ : $3319.19,2945.40,2870.80,1883.87,1589.02$. m.p.: $60.3-61.2^{\circ} \mathrm{C}$. ${ }^{1} \mathrm{H}$ NMR $(500 \mathrm{MHz}$, Chloroform- $d$ ) $\delta 7.44-7.37(\mathrm{~d}, J=8.79 \mathrm{~Hz}, 2 \mathrm{H}), 6.89-6.82(\mathrm{~d}, J=8.80 \mathrm{~Hz}, 2 \mathrm{H}), 4.12(\mathrm{t}$, $J=6.0 \mathrm{~Hz}, 2 \mathrm{H}), 3.87(\mathrm{t}, J=5.9 \mathrm{~Hz}, 2 \mathrm{H}), 2.05(\mathrm{~m}, J=5.9 \mathrm{~Hz}, 2 \mathrm{H}), 1.81(\mathrm{~s}, 1 \mathrm{H}(\mathrm{OH})) .{ }^{13} \mathrm{C}$ NMR (126 MHz, Chloroform-d) $\delta$ 159.31, 132.82, 128.77, 115.36, 77.50, 77.25, 76.99, $65.88,60.40,32.12$. (The ${ }^{1} \mathrm{H},{ }^{13} \mathrm{C}$, g-COSY and g-HSQC NMR spectra of S3 are depicted in Figure S1-S4 in the Supplementary Information.) Anal. Calcd. for $\mathrm{C}_{18} \mathrm{H}_{22} \mathrm{O}_{4} \mathrm{~S}_{2}$ : C 58.99, $\mathrm{H}$ 6.05, S 17.50. Found: C 58.96, H 6.01, S 17.42. HRMS (ESI) for $\mathrm{C}_{18} \mathrm{H}_{22} \mathrm{O}_{4} \mathrm{~S}_{2}$ calculated $[\mathrm{M}+\mathrm{H}]^{+}:$366.0960. Found: 366.0960.

$\mathbf{S}_{2}\left(\mathrm{Ph}\left(\mathrm{CH}_{2}\right)_{6} \mathrm{OH}\right)_{2}$ (S6). Yield: $30.3 \mathrm{~g}$ (32 mol\%). Pale yellow powder. FTIR (neat, $\left.\mathrm{cm}^{-1}\right)$ : 3424.97, 3372.48, 2937.83, 2925.88, 2864.63, 1735.82, 1589.27. m.p. $59.4-60.6$ 으. ${ }^{1} \mathrm{H}$ NMR (500 MHz, Chloroform- $d$ ): $\delta 7.33-7.26(\mathrm{~d}, J=8.7 \mathrm{~Hz}, 2 \mathrm{H}), 6.76-6.71$ (d, $J=8.8$ $\mathrm{Hz}, 2 \mathrm{H}), 3.86(\mathrm{t}, J=6.5 \mathrm{~Hz}, 2 \mathrm{H}), 3.58(\mathrm{t}, J=6.6 \mathrm{~Hz}, 2 \mathrm{H}), 1.76-1.66(\mathrm{~m}, 2 \mathrm{H}), 1.57-1.48$ $(\mathrm{m}, 2 \mathrm{H}), 1.47-1.30(\mathrm{~m}, 4 \mathrm{H}+1 \mathrm{H}(\mathrm{OH})) \cdot{ }^{13} \mathrm{C}$ NMR $(126 \mathrm{MHz}$, Chloroform- $d): \delta 159.67$, 132.95, 132.71, 128.45, 115.35, 77.50, 77.25, 76.99, 68.20, 63.11, 32.89, 29.38, 26.09, 25.75. (The ${ }^{1} \mathrm{H},{ }^{13} \mathrm{C}, \mathrm{g}$-COSY, g-HSQC NMR spectra of S6 are depicted in Figure S5-S8 in the Supplementary Information.) Anal. Calcd. for $\mathrm{C}_{24} \mathrm{H}_{34} \mathrm{O}_{4} \mathrm{~S}_{2}$ : C 63.97, H 7.60, S 14.23. Found: $\mathrm{C}$ 63.72, $\mathrm{H}$ 7.54, $\mathrm{S}$ 14.05. HRMS (ESI) for $\mathrm{C}_{24} \mathrm{H}_{34} \mathrm{O}_{4} \mathrm{~S}_{2}$ calculated $[\mathrm{M}+\mathrm{H}]^{+}$: 450.1899. Found: 450.1896.

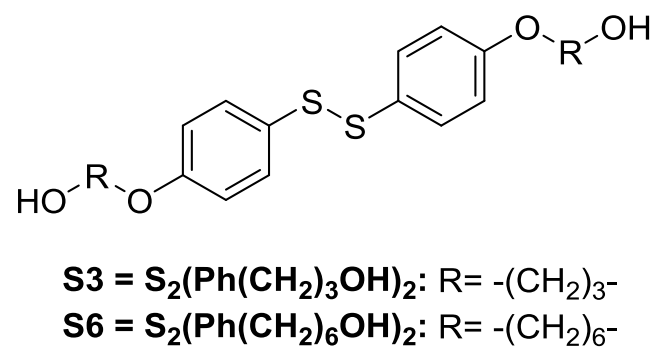

Figure 1. Chemical structure of bis[4-(3'-hydroxypropyloxy)phenyl]disulfide (S3) and bis[4-(6'hydroxyhexoxy)phenyl]disulfide (S6) 


\section{Synthesis of waterborne polyurethane-urea dispersions}

The synthesis of the PUU dispersions was carried out as summarized in Figure 2 using the formulation in Table 1. In order to obtain the disulfide-containing prepolymer, PolyTHF $\left(\mathrm{M}_{\mathrm{w}}=2000 \mathrm{~g} \cdot \mathrm{mol}^{-1}\right)$, DMPA, IPDI and $\mathrm{S}_{2}\left(\mathrm{Ph}\left(\mathrm{CH}_{2}\right)_{3} \mathrm{OH}\right)_{2}(\mathrm{~S} 3)$ or $\mathrm{S}_{2}\left(\mathrm{Ph}\left(\mathrm{CH}_{2}\right)_{6} \mathrm{OH}\right)_{2}(\mathrm{~S} 6)$ were fed together into a $100 \mathrm{~mL}$ jacketed glass reactor equipped with a mechanical stirrer and a condenser. Next, DBTL (0.7-0.9 wt\% of reactants) as catalyst and MEK (55-65 wt\%) as solvent were added and the mixture was stirred for 105-140 min (depending on the formulation as shown in Table 1 ) at $80^{\circ} \mathrm{C}$ under refluxing conditions. The amount of DMPA added in the synthesis was constant (3 wt\% of reactants), while the amount of S3 or S6 varied as shown in Table 1. After the prepolymer synthesis, the isocyanate concentration reduced to the theoretical level as determined by back titration and the mixture was cooled down to room temperature and neutralized with TEA (100 mol\% of DMPA). Then, deionized water (100 wt\%) was added dropwise to obtain a dispersion. Finally, the chain extender was added to react with the residual NCO groups of the dispersed prepolymer for $30 \mathrm{~min}$. MEK was removed from the filtered dispersion by evaporation using a rotary evaporator at 243 mbar so that approximately $45 \mathrm{~mL}$ of a waterborne PUU dispersion was obtained with a solids content of $30 \mathrm{wt} \%$. The dispersions were named according to their varying amount and type of chain extender, $L$ (linear obtained with HDA) and X (crosslinked obtained with DETA) followed by an indication of the amount and type of disulfide $\mathrm{S}_{2}\left(\mathrm{Ph}\left(\mathrm{CH}_{2}\right)_{3} \mathrm{OH}\right)_{2}(\mathrm{~S} 3)$ or $\mathrm{S}_{2}\left(\mathrm{Ph}\left(\mathrm{CH}_{2}\right)_{6} \mathrm{OH}\right)_{2}$ (S6). For example, a sample called 1.8X$0.56 \mathrm{~S} 3$ contains $1.8 \mathrm{wt} \%$ of DETA combined with $0.56 \mathrm{eq}$. of IPDI of the aromatic disulfide $\mathrm{S}_{2}\left(\mathrm{Ph}\left(\mathrm{CH}_{2}\right)_{3} \mathrm{OH}\right)_{2}(\mathrm{~S} 3)$, while $1.8 \mathrm{X}-0.56 \mathrm{~S} 6$ has the same formulation where the alternative aromatic disulfide $\mathrm{S}_{2}\left(\mathrm{Ph}\left(\mathrm{CH}_{2}\right)_{6} \mathrm{OH}\right)_{2}(\mathrm{~S} 6)$ with longer alkyl chain is introduced instead.

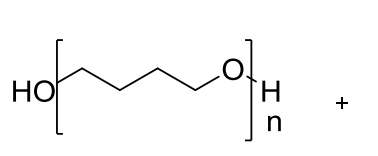

PolyTHF

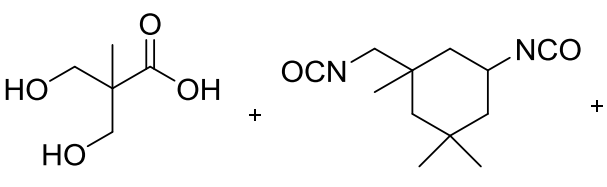

DMPA

IPDI

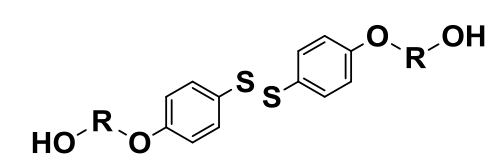

$\mathrm{R}=-\left(\mathrm{CH}_{2}\right)_{3}-: \mathrm{S}_{\mathbf{2}}\left(\mathrm{Ph}\left(\mathrm{CH}_{2}\right)_{3} \mathrm{OH}\right)_{2}$ (S3) $\mathrm{R}=-\left(\mathrm{CH}_{2}\right)_{6^{-}}: \mathrm{S}_{2}\left(\mathrm{Ph}\left(\mathrm{CH}_{2}\right)_{6} \mathrm{OH}\right)_{2}(\mathrm{~S} 6)$

DBTL, MEK

$80^{\circ} \mathrm{C}, \pm 2 \mathrm{~h}$

OCNmunnmm NCO

PU prepolymer

i. TEA, deionized $\mathrm{H}_{2} \mathrm{O}$

ii. $30 \mathrm{~min}, \mathrm{RT}$

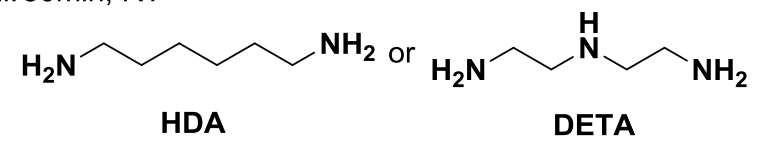

iii. MEK removal (243 mbar)

\section{Waterborne PUU dispersion}

Figure 2. Scheme of synthesis procedure of waterborne PUU dispersion. 
Table 1. Formulation (based on mol eq.) of the different PUU syntheses based on disulfide S3 and S6.

\begin{tabular}{c|c|c|c|c|c|c|c|c|c}
\hline \multicolumn{2}{c|}{ Sample } & DMPA & IPDI & PolyTHF & S3 & S6 & HDA & DETA & Time (min) \\
\hline \multirow{4}{*}{ L-S3 } & $\mathbf{2 . 5 L - 0 . 4 4 S 3 ~}$ & 0.18 & 1 & 0.20 & 0.44 & $/$ & 0.18 & $/$ & 120 \\
& $\mathbf{2 . 5 L - 0 . 5 4 S 3}$ & 0.16 & 1 & 0.13 & 0.54 & $/$ & 0.17 & $/$ & 105 \\
& $\mathbf{2 . 5 L - 0 . 5 9 S 3}$ & 0.15 & 1 & 0.10 & 0.59 & $/$ & 0.16 & $/$ & 110 \\
& $\mathbf{1 . 8 L - 0 . 5 6 S 3}$ & 0.17 & 1 & 0.15 & 0.56 & $/$ & 0.13 & $/$ & 130 \\
\hline L-S6 & $\mathbf{1 . 8 L - 0 . 5 6 S 6}$ & 0.17 & 1 & 0.15 & $/$ & 0.56 & 0.13 & $/$ & 140 \\
\hline & $\mathbf{2 . 5 X - 0 . 4 4 S 3}$ & 0.18 & 1 & 0.20 & 0.44 & $/$ & $/$ & 0.18 & 120 \\
X-S3 & $\mathbf{2 . 5 X - 0 . 5 4 S 3}$ & 0.16 & 1 & 0.13 & 0.54 & $/$ & $/$ & 0.17 & 105 \\
& $\mathbf{2 . 5 X - 0 . 5 9 S 3}$ & 0.15 & 1 & 0.10 & 0.59 & $/$ & $/$ & 0.16 & 110 \\
& $\mathbf{1 . 8 X - 0 . 5 6 S 3}$ & 0.17 & 1 & 0.15 & 0.56 & $/$ & $/$ & 0.13 & 130 \\
\hline X-S6 & $\mathbf{1 . 8 X - 0 . 5 6 S 6}$ & 0.17 & 1 & 0.15 & $/$ & 0.56 & $/$ & 0.13 & 140 \\
\hline
\end{tabular}

Two series of dispersions were synthesized. In a first series, linear polymers were prepared. Using $\mathrm{S}_{2}\left(\mathrm{Ph}_{(}\left(\mathrm{CH}_{2}\right)_{3} \mathrm{OH}\right)_{2}$ (S3) as the self-healing moiety, three linear (L-S3) PUUs were synthesized varying the amount of S3 from 0.44 eq. of IPDI for $2.5 \mathrm{~L}-0.44 \mathrm{~S} 3$ and 0.54 eq. for $2.5 \mathrm{~L}-0.54 \mathrm{~S} 3$ to 0.59 eq. for $2.5 \mathrm{~L}-0.59 \mathrm{~S} 3$ (Table 1 ). In order to obtain a softer material and understand the influence of the urea groups, an additional linear PUU (1.8L-0.56S3) was obtained by lowering the amount of HDA to $1.8 \mathrm{wt} \%$ of reactants, while keeping the amount of IPDI and DMPA constant. Another polymer dispersion (1.8L$0.56 \mathrm{S6}$ ) was obtained by using the more flexible self-healing moiety $\mathrm{S}_{2}\left(\mathrm{Ph}\left(\mathrm{CH}_{2}\right)_{6} \mathrm{OH}\right)_{2}(\mathrm{~S} 6)$ for the same formulation of the S3-based alternative (1.8L-0.56S3). The second series of polymer dispersions is formed by the cross-linked versions of the first series that were obtained by changing the chain extender from HDA to DETA. A schematic overview of the different series is depicted in Figure 3. 


\section{Linear PUUs}

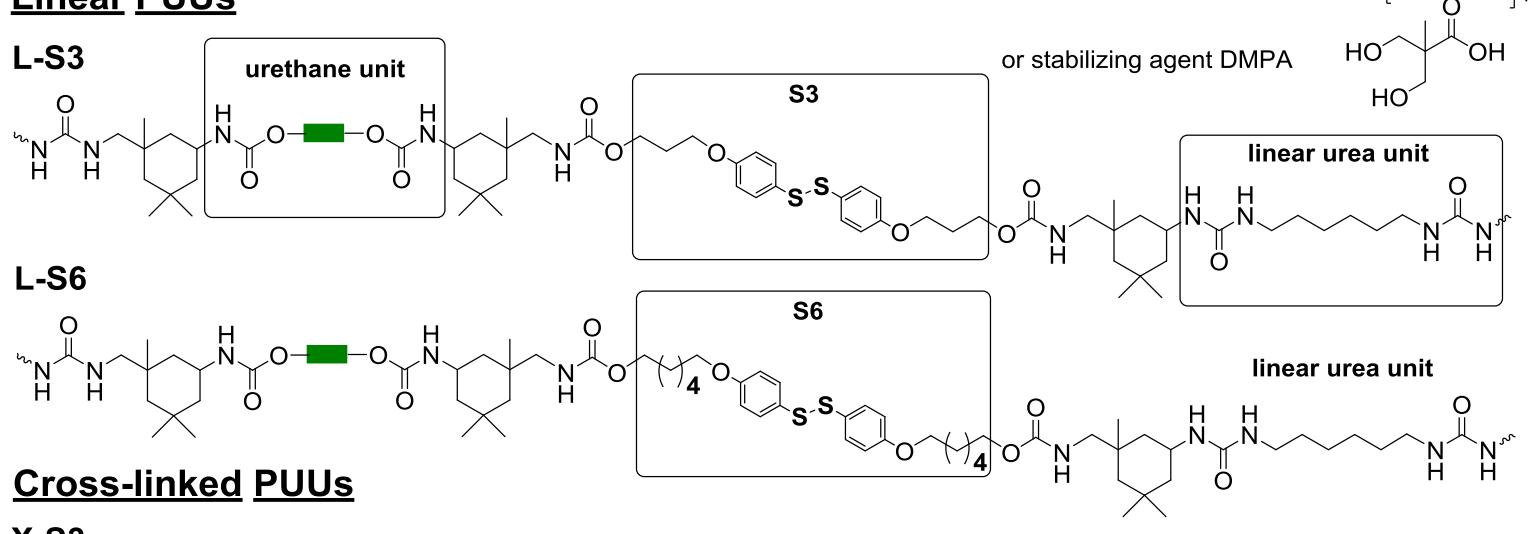

X-S3

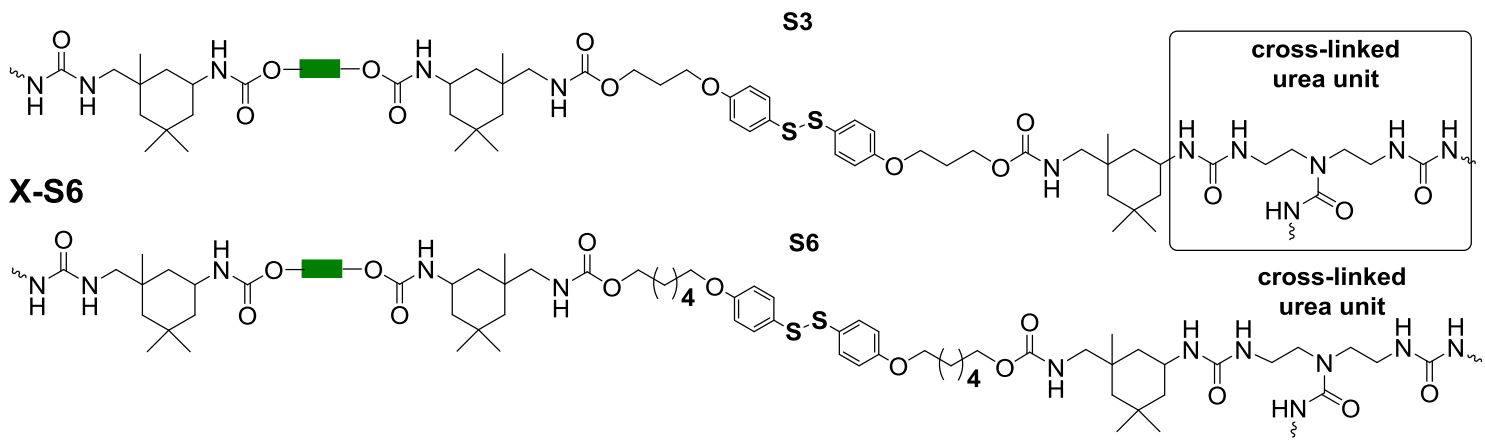

Figure 3. Schematic of linear PUUs (L-S3 and L-S6) and cross-linked PUUs (X-S3 and X-S6).

\section{Characterization}

Infrared spectra were recorded in a FTIR spectrometer (Bruker). All melting points were measured in a Büchi Melting Point B-540. The NMR spectra were recorded at $500 \mathrm{MHz}$ for ${ }^{1} \mathrm{H}-\mathrm{NMR}$, and $126 \mathrm{MHz}$ for ${ }^{13} \mathrm{C}\{\mathrm{H}\}-\mathrm{NMR}$ in $\mathrm{CDCl}_{3}$ at room temperature. The data are reported as $\mathrm{s}=$ singlet, $\mathrm{d}=$ doublet, $\mathrm{t}=$ triplet, $\mathrm{m}=$ multiplet, coupling constant(s) in $\mathrm{Hz}$, integration. Elemental analysis was carried out using a TruSpec Micro (LECO) analyzer. HRMS-analysis was performed with a LC/Q-TOF with Agilent Jet Stream ESI ionization source.

The NCO content of the PU prepolymer was determined by means of a back titration with $\mathrm{HCl}$ of the excess of dibutylamine (DBA) molecules, which were added to neutralize the free NCO-groups of the PU.[44-46] The particle sizes and distributions were measured by hydrodynamic chromatography (HDC) with a Matec CHDF3000 instrument equipped with UV detector operating at $254 \mathrm{~nm}$ and a PL-PSDA Type 2 (Agilent) column using a carrier flux of $1 \mathrm{~mL} \cdot \mathrm{min}^{-1}$. For these measurements, samples were diluted to $1 \%$ solids content, passed through a $1.2 \mu \mathrm{m}$ nylon filter and injected with an autosampler (25 $\mu \mathrm{L})$. The eluent was an aqueous solution of sodium dihydrogenphosphate $\left(0.24 \mathrm{~g} . \mathrm{L}^{-1}\right)$, sodium dodecyl sulfate $\left(0.5 \mathrm{~g} . \mathrm{L}^{-1}\right)$, Brij35 (poly alkylenglycolether, $\left.2 \mathrm{~g} \cdot \mathrm{L}^{-1}\right)$ and sodium azide $\left(0.2 \mathrm{~g} . \mathrm{L}^{-1}\right)$ was used. Periodic calibration of the system was performed using narrowly dispersed polystyrene standards. The molecular weights of the dried films which could completely 
dissolve in THF were determined by injecting them into a Size Exclusion Chromatography/Gel Permeation Chromatography (SEC/GPC) instrument after filtering them. The instrument consisted of a pump (LC-20A, Shimadzu), an autosampler (Waters 717), a differential refractometer (Waters 2410), a UV detector measuring at 262nm (Waters 2487) and three columns in series (Styragel HR2, HR4 and HR6, with pore sizes ranging from $102-106 \AA$ ). Chromatograms were obtained at $35^{\circ} \mathrm{C}$ using a THF flow rate of $1 \mathrm{~mL} \cdot \mathrm{min}^{-1}$. A series of polystyrene (PS) standards in the range of 580-3 $848000 \mathrm{~g} \cdot \mathrm{mol}^{-1}$ were used to obtain the calibration curve which provided $\mathrm{M}_{\mathrm{w}} \mathrm{s}$ of the polymer relative to PS.

Films with a thickness of $0.50-0.75 \mathrm{~mm}$ were obtained by casting the dispersion in silicon molds $(25 \times 55 \mathrm{~mm})$. The films were first dried for 1 day at $25^{\circ} \mathrm{C}$ and subsequently for 2 days at $60^{\circ} \mathrm{C}$ after which they were equilibrated for 3 days at $25^{\circ} \mathrm{C}$. Dynamic mechanical analysis (DMA) was carried out in a TA Instruments DMA Q800 equipped with a liquid nitrogen cooling system. The measurements were performed in tensile geometry at a fixed frequency of $1 \mathrm{~Hz}$, an initial static force of $0.35 \mathrm{~N}$ and a constant strain of $0.03 \%$ with the static force $20 \%$ larger than the dynamic one. The samples (typical size $=10 \times 10 \times 0.5$ $\mathrm{mm}$ ) were cooled down to $-150 /-100^{\circ} \mathrm{C}$ and heated with a rate of $4^{\circ} \mathrm{C} \cdot \mathrm{min}^{-1}$ till the temperature at which the minimum dynamic force of $0.01 \mathrm{~N}$ was hit. Stress-strain measurements were carried out on dumbbell type specimen at $23^{\circ} \mathrm{C}$ and $50 \% \mathrm{RH}$, meeting the requirements of ISO 291-23/50-class 1, on a universal testing machine Z050/zmart.pro with testcontrol by Zwick $\mathrm{GmbH}$ at a cross-head velocity of $25 \mathrm{~mm} \mathrm{~min}{ }^{-1}$. For each experiment, the averages of 3-5 replicate measurements are reported here. For the scratch closure experiments, scratches were made with a depth of $\pm 75 \%$ of their thickness $( \pm 0.7 \mathrm{~mm})$ using a razor blade with a thickness of $0.40 \mathrm{~mm}$ and subsequently closure at $80^{\circ} \mathrm{C}$ was followed using an optical microscope (Nikon Eclipse LV100ND). The rheological data were obtained from a stress-controlled Anton Paar Physica MCR101 rheometer using parallel plate geometry (plate $\emptyset=8 \mathrm{~mm}$, disk-shaped specimens: $\pm 10 \mathrm{~mm}$ in diameter and $0.50-0.75 \mathrm{~mm}$ in thickness). Frequency sweeps $(0.001-20 \mathrm{~Hz})$ at a strain of $0.5 \%$ were conducted at fixed temperatures ranging from $70-130^{\circ} \mathrm{C}$.

\section{Results and discussion}

All synthesized PUU dispersions were stable and coagulum free. The particle size distributions (Figure S9, Supplementary Information), determined by HDC, show a broad variation with average particle sizes in the range of 50 to $300 \mathrm{~nm}$, since the chain extension step that was performed after dispersion of the PUU in water is more difficult to control on this small scale. Homogeneous and transparent films were obtained in all cases (Figure 4). By increasing the disulfide content, the molecular weights $\left(\mathrm{M}_{\mathrm{w}}\right)$ of the linear S3based (L-S3) PUUs decreased (Table 2). This was due to the fact that an increase of disulfide inevitably implies a decrease of the macrodiol PolyTHF (Table 1) and therefore lower molecular weights were obtained at a similar degree of polymerization. On the other hand, the molecular weight increased when S6 was used instead S3, which might be due to the higher flexibility of S6 that could lead to better availability of the alcohol functionalities when long chain lengths were obtained during polymerization leading to higher conversion levels that yield higher molecular weights. 


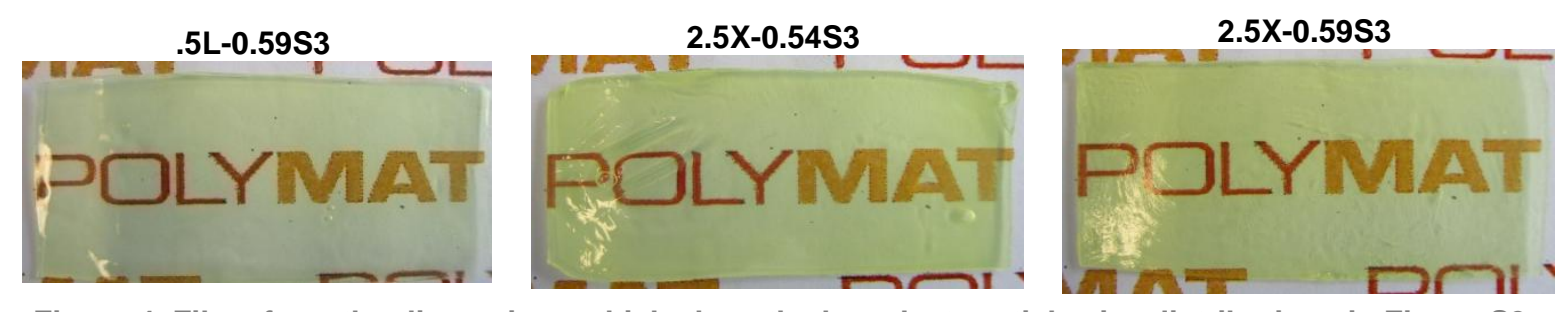

Figure 4. Films from the dispersions which show the broadest particle size distributions in Figure S9.

Table 2. Polymer characteristics of PUUs based on $\mathrm{S}_{2}\left(\mathrm{Ph}\left(\mathrm{CH}_{2}\right)_{3 / 6} \mathrm{OH}\right)_{2}(\mathrm{~S} 3 / \mathrm{S} 6)$.

\begin{tabular}{|c|c|c|c|c|c|}
\hline & \multirow{2}{*}{ Sample } & \multicolumn{3}{|c|}{ GPC (IR) } & DMA \\
\hline & & $M_{n}(k D a)$ & $M_{w}(k D a)$ & Đ & $\mathrm{T}_{\mathrm{g}}\left({ }^{\circ} \mathrm{C}\right)\left(=\mathrm{T}_{\max } \operatorname{Tan} \delta\right)$ \\
\hline \multirow{4}{*}{ L-S3 } & $2.5 \mathrm{~L}-0.44 \mathrm{~S} 3$ & 34 & 65 & 1.9 & 43 \\
\hline & $2.5 \mathrm{~L}-0.54 \mathrm{~S} 3$ & 23 & 44 & 1.9 & 67 \\
\hline & 2.5L-0.59S3 & 20 & 39 & 1.9 & 75 \\
\hline & $1.8 \mathrm{~L}-0.56 \mathrm{~S} 3$ & 22 & 45 & 2.1 & 59 \\
\hline L-S6 & $1.8 \mathrm{~L}-0.56 \mathrm{~S} 6$ & 35 & 71 & 2.0 & 27 \\
\hline \multirow{4}{*}{53} & $2.5 \mathrm{X}-0.44 \mathrm{~S} 3$ & \multirow{5}{*}{\multicolumn{3}{|c|}{ Insoluble in THF }} & 53 \\
\hline & $2.5 \mathrm{X}-0.54 \mathrm{~S} 3$ & & & & 73 \\
\hline & $2.5 \mathrm{X}-0.59 \mathrm{~S} 3$ & & & & 77 \\
\hline & $1.8 \mathrm{X}-0.56 \mathrm{~S} 3$ & & & & 64 \\
\hline X-S6 & $1.8 \mathrm{X}-0.56 \mathrm{~S} 6$ & & & & 33 \\
\hline
\end{tabular}

The DMA results of the PUUs are depicted in Figures 5-6. First of all, a secondary relaxation can be observed around $-140^{\circ} \mathrm{C}$, similar to the ones observed for bisphenol $\mathrm{A}$ polycarbonate, which can be linked to the presence of closely interconnected aromatic rings, in this case connected through dynamic disulfide bonds.[47,48] Additionally, two different glass transition regions can be observed for all PUUs based on S3 (Figure 5B and $D)$. While the low $T$ glass transition temperature $\left(T_{g}\right)$ is situated around $-70^{\circ} \mathrm{C}\left(T_{g}\right.$ of PolyTHF $=-77^{\circ} \mathrm{C}$ ), a second broader transition could be observed at higher temperature. This glass transition, which can be followed easily by looking at the peak of the $\tan \delta$ as this is also considered as a measure for the $T_{g}$, differed significantly between samples as depicted in Figure 5 and in Table 2. In the samples containing the same amount of chain extender, the high temperature $T_{g}$ increased with the content of $S 3$ in the polymer, because more aromatic moieties were incorporated into the backbone. In addition, this $T_{g}$ increased with the content of chain extender because of the augmentation of the urea groups that led to a higher degree of $\mathrm{H}$-bonding. Figure 5 also shows that cross-linking led to an increase of the high temperature $T_{g}$ and to a rubbery plateau, which is a fingerprint of the polymer network, at higher temperatures. Moreover, Figure 6 depicts that the storage modulus at room temperature and the high temperature $T_{g}$ strongly decreased when the more flexible disulfide moiety S6 was incorporated instead of S3. 

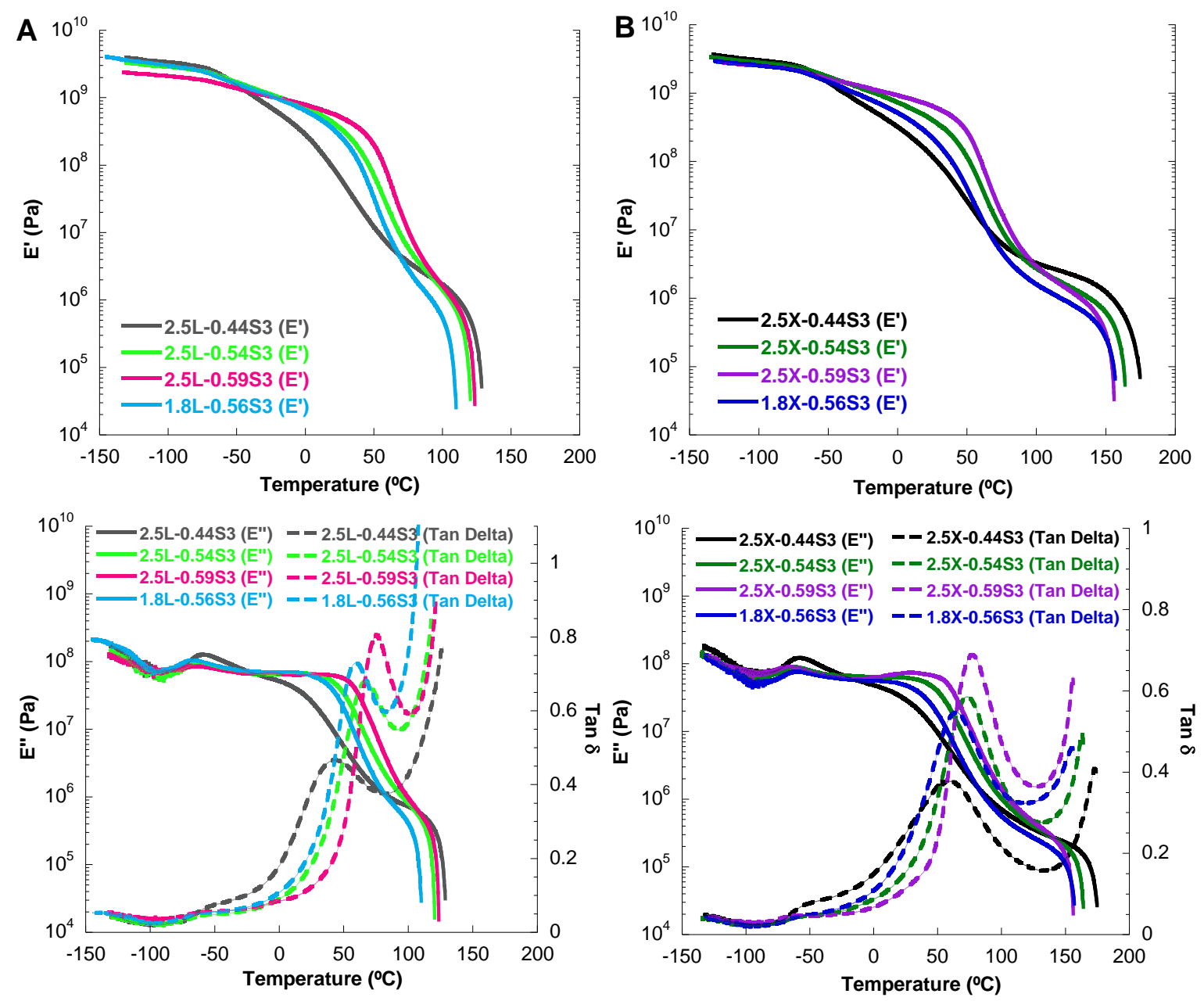

Figure 5. . Storage modulus (E'), loss modulus (E’') and Tan $\delta$ vs. T, of linear ( $A$; C) and cross-linked (B; D) PUUs based on S3.
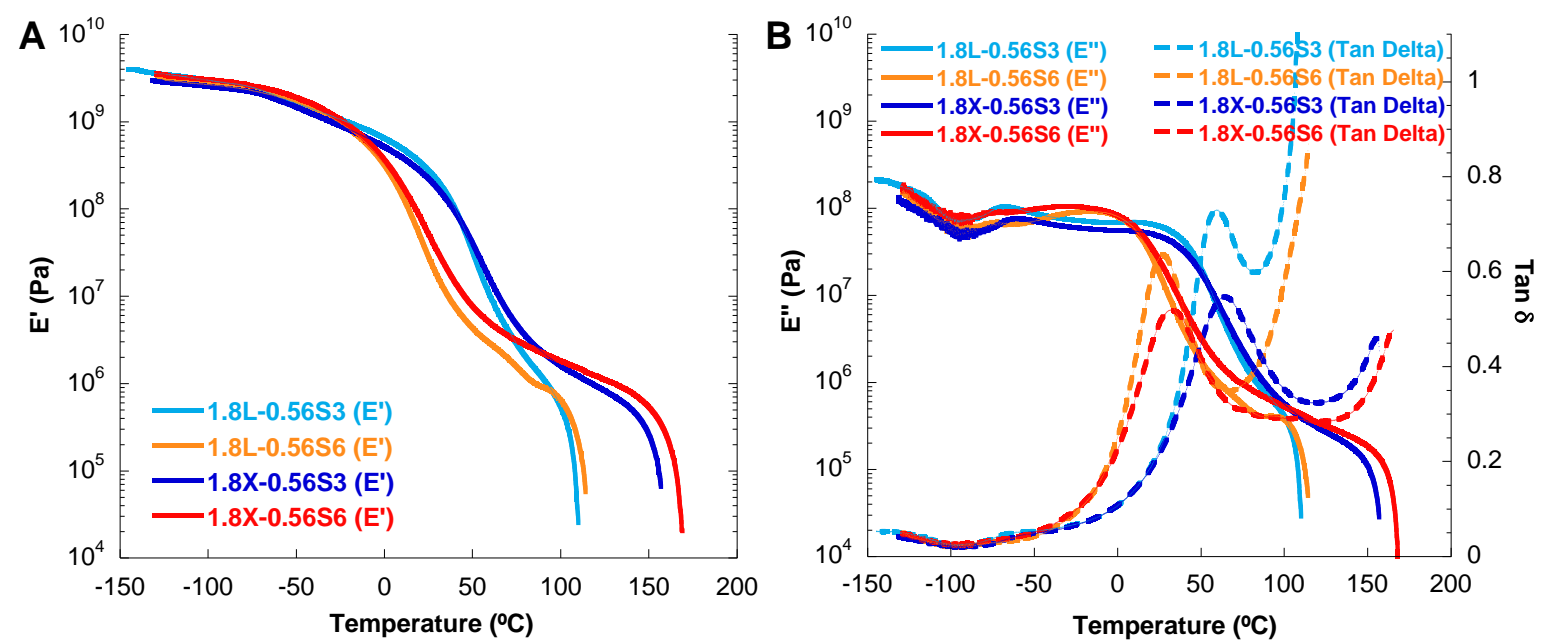

Figure 6. Storage modulus (E') (A), loss modulus (E’') and Tan $\delta(B)$ vs. T of $1.8 \mathrm{~L} / \mathrm{X}-0.56 \mathrm{~S} 3$ in comparison with $1.8 \mathrm{~L} / \mathrm{X}-0.56 \mathrm{~S} 6$. 
Alternatively, the polymer structure also influenced the tensile test results as can be seen in Table 3 and Figure 7. By increasing the amount of the self-healing moiety (S3) or chain extender or by introducing cross-linking points into the PUU material, the rigidity and strength of the material increased, as can be seen at the increasing value of the Young's modulus, yield strength $\left(\sigma_{\mathrm{y}}\right)$ and tensile strength at fracture $\left(\sigma_{\mathrm{f}}\right)$. However, at the same time they decreased the elongation at fracture $\left(\varepsilon_{f}\right)$, which is most obvious for the most rigid PUU 2.5X-0.59S3 (Figure 7A). On the other hand, by introducing the more flexible selfhealing moiety (S6) into the polymer backbone, the strength and rigidity of the PUUs decreased (Figure 7B). Figure 7 shows that several of the PUUs synthesized in this work showed tensile strengths at fracture in the range of 16-18.5 MPa, which are high values considering that the cross-head speed used was low $\left(25 \mathrm{~mm} \cdot \mathrm{min}^{-1}\right.$ versus 100-500 $\mathrm{mm} \cdot \mathrm{min}^{-1}$ used in the aforementioned studies)[23,24,33,34] and that the tensile strength and Young's modulus generally increase with the cross-head speed.[49,50]

Table 3. Tensile testing results of PUUs based on $\mathrm{S}_{2}\left(\mathrm{Ph}\left(\mathrm{CH}_{2}\right)_{3} \mathrm{OH}\right)_{2}(\mathrm{~S} 3)$ or $\mathrm{S}_{2}\left(\mathrm{Ph}\left(\mathrm{CH}_{2}\right)_{6} \mathrm{OH}\right)_{2}(\mathrm{~S} 6)$.

\begin{tabular}{c|c|c|c|c|c}
\hline \multicolumn{2}{c|}{ Sample } & $\begin{array}{c}\text { Young's } \\
\text { modulus (MPa) }\end{array}$ & $\sigma_{\mathrm{y}}$ (MPa) & $\sigma_{f}(\mathrm{MPa})$ & $\mathcal{E}_{\mathrm{f}}(\%)$ \\
\hline & $\mathbf{2 . 5 L - 0 . 4 4 S 3}$ & $31.2 \pm 1.9$ & $/$ & $12.5 \pm 0.7$ & $460 \pm 10$ \\
L-S3 & $\mathbf{2 . 5 L - 0 . 5 4 S 3}$ & $321.2 \pm 1.1$ & $10.3 \pm 0.3$ & $15.2 \pm 0.5$ & $240 \pm 20$ \\
& $\mathbf{2 . 5 L - 0 . 5 9 S 3}$ & $707.8 \pm 11.6$ & $21.2 \pm 0.5$ & $17.7 \pm 0.4$ & $135 \pm 10$ \\
& $\mathbf{1 . 8 L - 0 . 5 6 S 3}$ & $207.2 \pm 6.8$ & $7.2 \pm 0.2$ & $11.6 \pm 0.3$ & $295 \pm 10$ \\
\hline L-S6 & $\mathbf{1 . 8 L - 0 . 5 6 S 6}$ & $15.1 \pm 1.1$ & $/$ & $8.3 \pm 0.3$ & $410 \pm 5$ \\
\hline & $\mathbf{2 . 5 X - 0 . 4 4 S 3}$ & $41.0 \pm 2.7$ & $/$ & $18.5 \pm 0.5$ & $450 \pm 5$ \\
X-S3 & $\mathbf{2 . 5 X - 0 . 5 4 S 3}$ & $340.3 \pm 6.4$ & $11.7 \pm 0.6$ & $18.0 \pm 1.0$ & $235 \pm 10$ \\
& $\mathbf{2 . 5 X - 0 . 5 9 S 3}$ & $751.9 \pm 12.9$ & $23.7 \pm 0.4$ & $13.6 \pm 3.0$ & $30 \pm 10$ \\
& $\mathbf{1 . 8 X - 0 . 5 6 S 3}$ & $278.5 \pm 7.2$ & $9.3 \pm 0.1$ & $16.3 \pm 0.3$ & $315 \pm 35$ \\
\hline X-S6 & $\mathbf{1 . 8 X - 0 . 5 6 S 6}$ & $27.9 \pm 1.9$ & $/$ & $9.5 \pm 0.2$ & $340 \pm 10$ \\
\hline
\end{tabular}
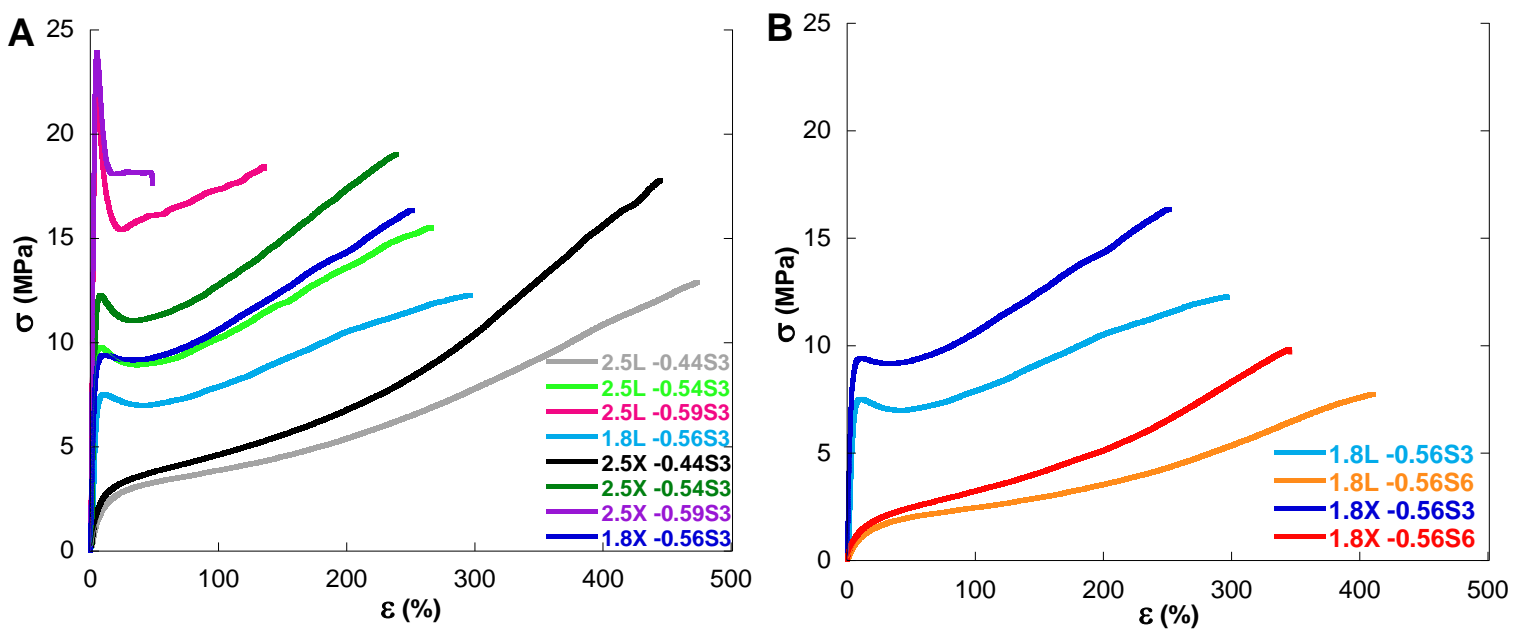

Figure 7. Stress-strain curves measured of PUUs based on S3 (A) and PUUs based on S6 (B) obtained at $23^{\circ} \mathrm{C}$ using a cross-head velocity of $25 \mathrm{~mm} \cdot \mathrm{min}^{-1}$. 
The results discussed above show that the combination of aromatic disulfides of different flexibility (S3 versus S6) and chain extenders with different functionalities (HDA versus DETA) allows the synthesis of PUUs with a wide range of mechanical properties. However, the self-healing ability of these materials should also be characterized. For selfhealing to take place, a certain degree of molecular mobility in the PUUs is required. Mobility is often related to the relaxation time $\left(\tau_{d}\right)$ that for a given temperature is the inverse of the frequency at which the crossover between the storage modulus ( $\left.G^{\prime}\right)$ and the loss modulus (G") occurs.[51-53] Master curves for G' and G' were obtained by performing frequency sweep measurements at different temperatures and applying the time-temperature superposition (TTS) principle. For the TTS principle to be valid, materials should not change their microstructure upon exposure to temperature, which is not always true for polymers based on supramolecular interactions or dynamic covalent bonds.[54]

In order to verify if the TTS principle is applicable for the materials presented here, the van-Gurp-Palmen-plots were constructed (Figures S10 and S11 in the Supplementary information). In these graphs, the phase angle $\delta$ is depicted versus the corresponding absolute value of the complex shear modulus $\left|\mathrm{G}^{*}\right|$ and the isothermal frequency curves should merge into a common line if the TTS principle holds.[55] In these polymers, however, the van-Gurp-Palmen-plots did not completely merge to a single line indicating that the materials underwent some change with temperature, likely due to the activation of the dynamic disulfide bonds at higher temperatures. This also explains the growing divergence between the isothermal frequency curves as the amount of disulfide compound S3 increased (Figure S6). Although the TTS principle does not hold equally well for all PUUs discussed here, this principle can still be useful to qualitatively study the timedependent relaxation processes for thermo-rheological complex materials. $[40,42,54,56-$ 62] Actually, by using horizontal $\left(a_{T}\right)$ and vertical shift factors $\left(b_{T}\right)$, an acceptable superposition could be achieved for the linear PUUs and the cross-linked 1.8X-0.56S3 and $1.8 \mathrm{X}-0.56 \mathrm{~S} 6$. For these polymers, the master curves were constructed using $80{ }^{\circ} \mathrm{C}$ as reference temperature. This temperature was chosen because it is high enough so the $T_{g}$ of all PUUs is surpassed and the materials are able to molecularly interdiffuse, but simultaneously it is low enough to avoid any possible degradation (e.g. by cleavage of urethane linkages $\geq 150^{\circ} \mathrm{C}$ ). [63] For the rest of cross-linked polymers, superposition was not good enough to obtain acceptable master curves at $80^{\circ} \mathrm{C}$.

The master curves at $80{ }^{\circ} \mathrm{C}$ for the linear polymers and the cross-linked 1.8X-0.56S3 and $1.8 \mathrm{X}-0.56 \mathrm{~S} 6$ are presented in Figure 8. The values for the crossover frequency $\omega_{\mathrm{d}}$, at which G' and G" intersect and which is indicated with an arrow (Figure 8), as well as those of the relaxation time $\tau_{d}$ are reported in Table 4 . From the values obtained from the master curves of the L-S3 (Figure 8A), it is clear that the mobility of the material decreased by either a too low amount of the self-healing moiety (S3) (e.g. soft 2.5L-0.44S3), as only a limited amount of disulfide bonds are present, or a too high disulfide content (S3) (e.g. rigid 2.5L-0.59S3), since dynamic exchange is restricted by the stiffness of the PUU backbone. Additionally, the mobility also decreased with the content of chain extender (HDA). Furthermore, it is remarkable that some of the cross-linked PUUs showed a G'-G' 
crossover point at $80^{\circ} \mathrm{C}$. Generally, for cross-linked polymers, no G'-G” crossover point is expected as the network prevents the material from flowing. However, when activated by temperature, the dynamic disulfide bonds present in the PUU backbone break the polymer chains between cross-linking points allowing the rearrangement of the network structure and therefore inducing some flow. This was the reason for the presence of G'-G" crossover in the PUUs cross-linked with the lowest DETA concentration (1.8\%, samples $1.8 \mathrm{X}-0.56 \mathrm{~S} 3$ and 1.8X-0.56S6). However, when the DETA concentration was increased to $2.5 \%$ (samples $2.5 \mathrm{X}-0.44 \mathrm{~S} 3,2.5 \mathrm{X}-0.54 \mathrm{~S} 3$ and $2.5 \mathrm{X}-0.59 \mathrm{~S} 3$ ) the network was so densely cross-linked that the exchange of some disulfide bonds did not allow sufficient flow of the material at $80^{\circ} \mathrm{C}$. In any case, Table 4 shows that, even for $1.8 \mathrm{X}-0.56 \mathrm{~S} 3$ and $1.8 \mathrm{X}-0.56 \mathrm{~S} 6$, the network reduced the mobility of the polymer.

A way to overcome these restrictions in the mobility of the PUUs, is by using the more flexible disulfide (S6) as shown in Figure 8B and Table 4. It is particularly remarkable that in the case of the cross-linked PUUs the relaxation time was reduced by a factor of 50 , whereas in the linear polymers $\tau_{d}$ decreased only by a factor of 2 , when comparing the S6based materials to their S3-based counterparts. This clearly indicates that dynamic covalent bonds placed in flexible moieties facilitate the rearrangement of polymer networks making the healing of cross-linked polymers possible under moderate conditions. From these results, it can therefore be concluded that although mechanical properties can influence the mobility of the system, ultimately the polymer architecture with the possibility of incorporating intramolecular interactions, dynamic bonds, cross-linking points and/or more or less flexible monomers has a decisive role on determining the final mobility and thus healing ability of the material.
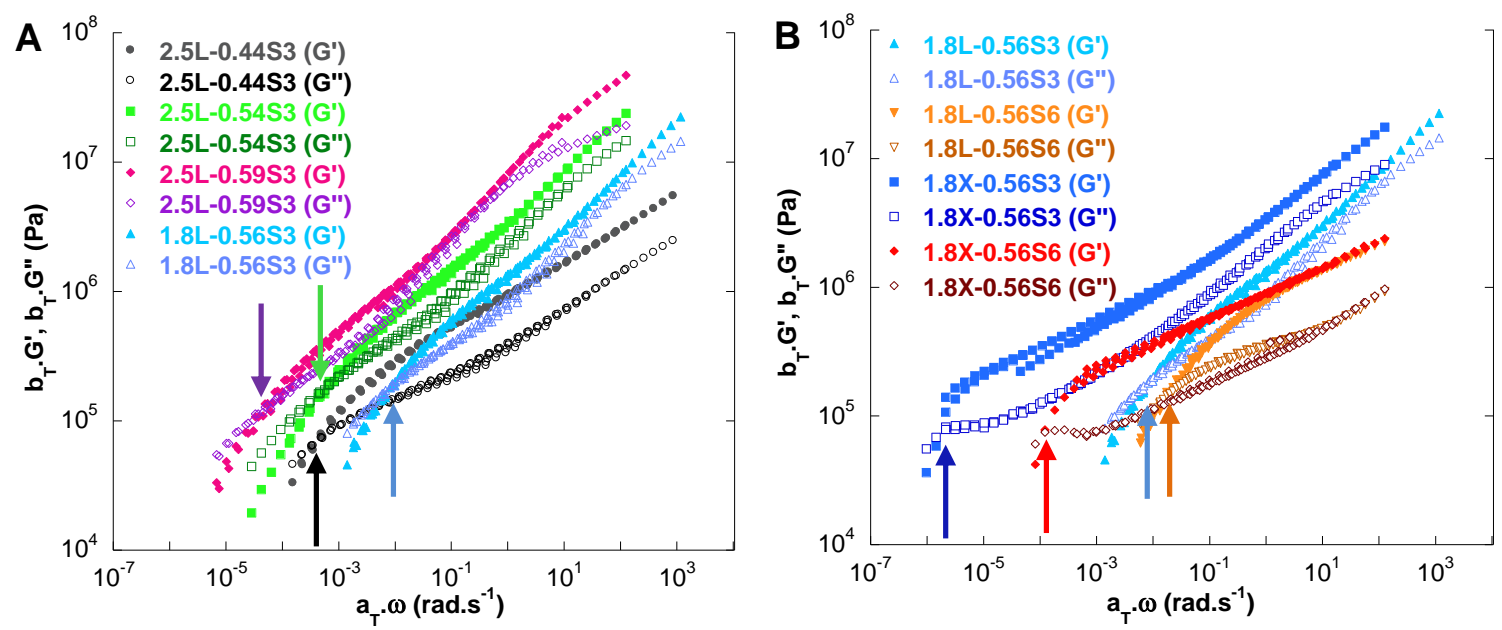

Figure 8. Master curves $\left(\mathrm{T}_{\text {ref }}=80^{\circ} \mathrm{C}\right)$ of the $\mathrm{L}-\mathrm{S} 3$ series $(\mathrm{A})$ and of $1.8 \mathrm{~L} / \mathrm{X}-0.56 \mathrm{~S} 3$ versus $1.8 \mathrm{~L} / \mathrm{X}-0.56 \mathrm{~S} 6(\mathrm{~B})$. 
Table 4. Characteristic values for G'-G"' crossover in the master curves $\left(T_{\text {ref }}=80^{\circ} \mathrm{C}\right)$ of the PUUs.

\begin{tabular}{c|c|c|c}
\hline \multicolumn{2}{c|}{ Sample } & $\omega_{\mathrm{d}}\left(\right.$ rad.s $\left.^{-1}\right)$ & $\tau_{\mathrm{d}}$ \\
\hline & $\mathbf{2 . 5 L}-\mathbf{0 . 4 4 S 3}$ & $4^{*} 10^{-4}$ & $4.5 \mathrm{~h}$ \\
L-S3 & $\mathbf{2 . 5 L - 0 . 5 4 S 3}$ & $6^{\star} 10^{-4}$ & $3 \mathrm{~h}$ \\
& $\mathbf{2 . 5 L}-\mathbf{0 . 5 9 S 3}$ & $5^{\star} 10^{-5}$ & $1.5 \mathrm{~d}$ \\
& $\mathbf{1 . 8 L}-\mathbf{0 . 5 6 S 3}$ & 0.008 & $13 \mathrm{~min}$ \\
\hline L-S6 & $\mathbf{1 . 8 L - 0 . 5 6 S 6}$ & 0.016 & $6.5 \mathrm{~min}$ \\
\hline X-S3 & $\mathbf{1 . 8 X - 0 . 5 6 S 3}$ & $2^{*} 10^{-6}$ & $36 \mathrm{~d}$ \\
\hline X-S6 & $\mathbf{1 . 8 X - 0 . 5 6 S 6}$ & $1^{*} 10^{-4}$ & $17.5 \mathrm{~h}$ \\
\hline
\end{tabular}

All the polymers in Table 4 show mobility and flow at $80 \stackrel{\circ}{\mathrm{C}}$ although the relaxation time $\left(\tau_{d}\right)$ varied from a few minutes to days. In order to test if the mobility of these PUUs also leads to self-healing, scratch closure tests were performed as a simple method to macroscopically assess the healing ability of materials. In Figures 9 and 10, the evolution of the scratches is depicted which showed that complete closure of the scratches could be achieved, although in most cases the time required $\left(t_{\text {scratch }}\right.$ ) was considerably longer than the relaxation time, $\tau_{d}$. This can be linked to the fact that scratch closure requires the creep deformation of the polymer over relatively large times, which is a complex viscoelastic process that implies a spectrum of retardation times.[56] Interestingly, there is a linear relationship between $t_{\text {scratch }}$ and $\tau_{d}$ (Figure 11). Nevertheless, it is noteworthy to mention that, contrary to the other examples, $t_{\text {scratch }}$ seemed shorter than the relaxation time $\left(\tau_{d}\right)$ for 1.8X-0.56S3. This might be explained by the fact that the higher cross-linking degree induces a delayed elastic recovery at higher temperatures leading to a strong scratch closing behaviour after already $1 \mathrm{~d}$, which supposedly promotes complete scratch closure at shorter healing times.[64-66] As the long scratch closure times needed at $80{ }^{\circ} \mathrm{C}$ may be an issue when considering the application of these materials, the effect of the healing temperature on the relaxation time was explored by using the TTS principle (Figure 12). Using the relatively hard $2.5 \mathrm{~L}-0.59 \mathrm{~S} 3$ as an example, increasing the healing temperature to $100^{\circ} \mathrm{C}$, the relaxation time will decrease to roughly $10^{3} \mathrm{~s}(0.28 \mathrm{~h})$. Using Figure 11 as a reference, $t_{\text {scratch }}$ is expected to decrease from days to about $4 \mathrm{~h}$. Next to playing with the flexibility of the polymer microstructure, further increasing the healing temperature might therefore be another way to overcome the mobility restrictions in order to develop stronger polymer networks with more efficient self-healing abilities. 


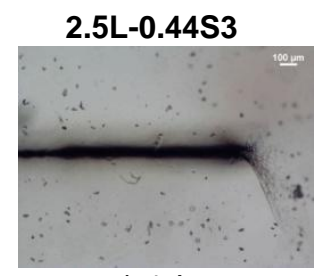

$\downarrow 1 \mathrm{~d}$

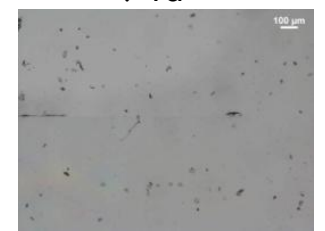

$\downarrow 2 \mathrm{~d}$
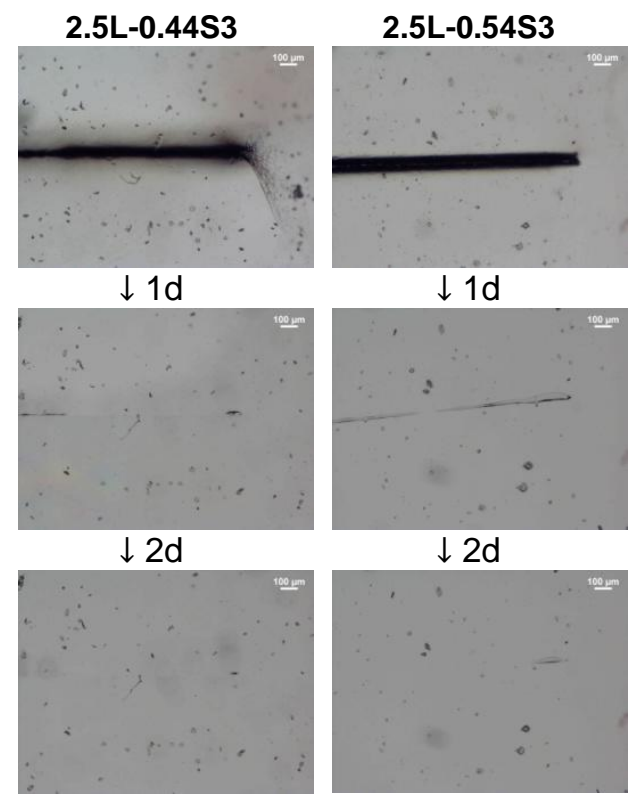

$\downarrow 1 \mathrm{~d}$

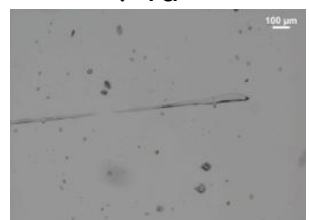

$\downarrow 2 d$
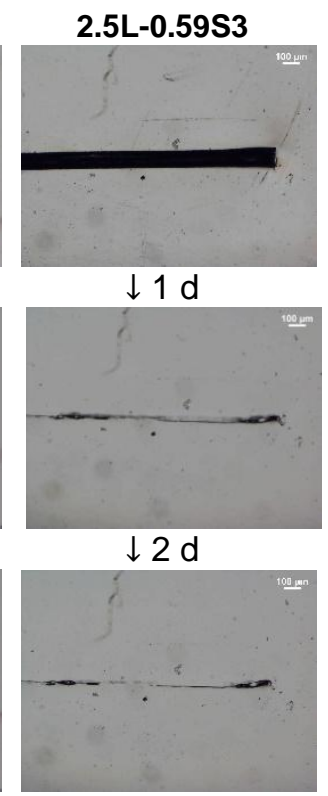

$\downarrow 1 \mathrm{~d}$
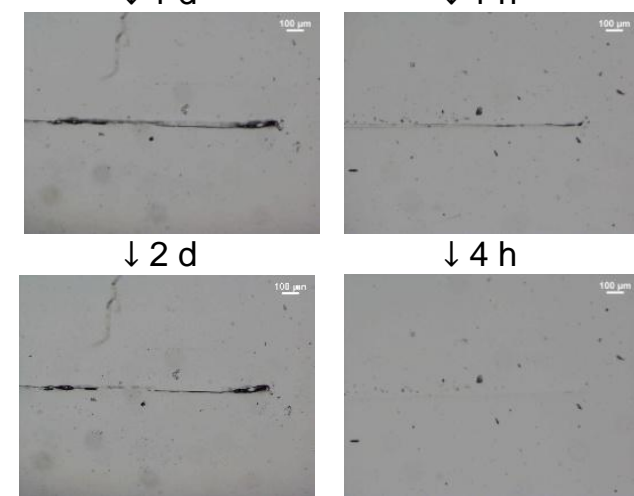

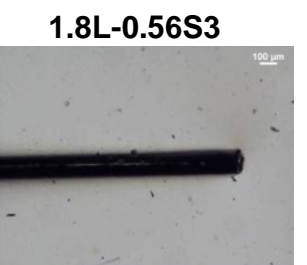

$\downarrow 1 \mathrm{~h}$

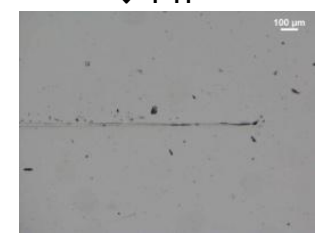

$\downarrow 4 \mathrm{~h}$

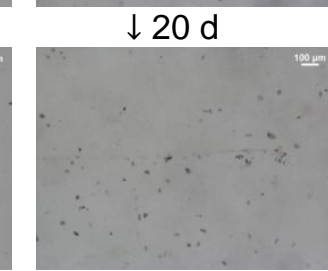

$1.8 \mathrm{X}-0.56 \mathrm{~S} 3$

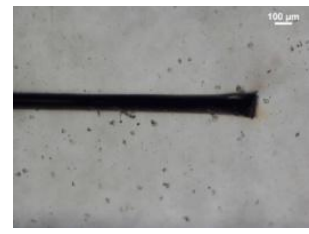

$\downarrow 1 \mathrm{~d}$

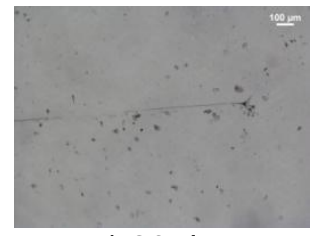

뜨뭉

Figure 9. Scratch closure at $80^{\circ} \mathrm{C}$ of PUUs based on $\mathrm{S}_{2}\left(\mathrm{Ph}\left(\mathrm{CH}_{2}\right)_{3} \mathrm{OH}\right)_{2}(\mathrm{~S} 3)$.

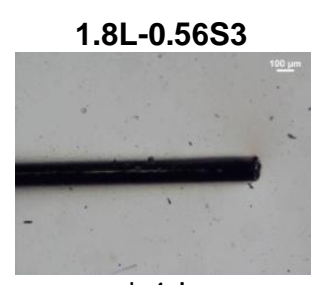

$\downarrow 1 \mathrm{~h}$

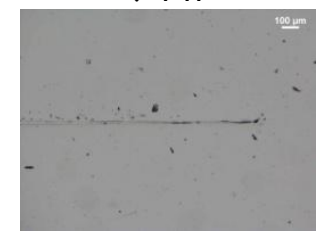

$\downarrow 4 \mathrm{~h}$

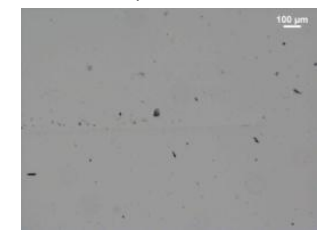

$1.8 \mathrm{X}-0.56 \mathrm{~S} 3$

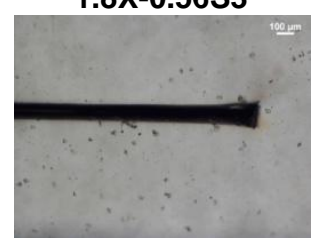

$\downarrow 4 \mathrm{~h}$

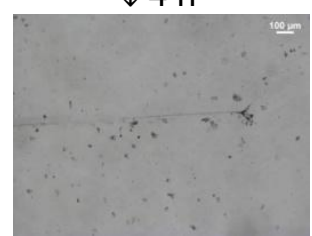

$\downarrow 20 \mathrm{~d}$

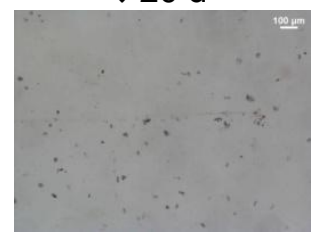

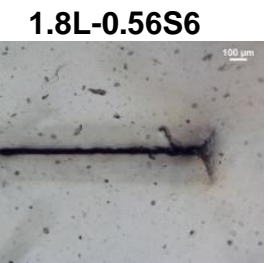

$\downarrow 1 \mathrm{~h}$

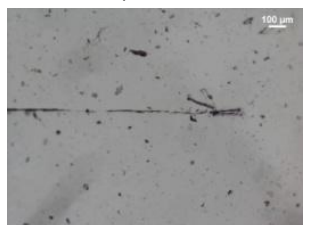

$\downarrow 4 \mathrm{~h}$

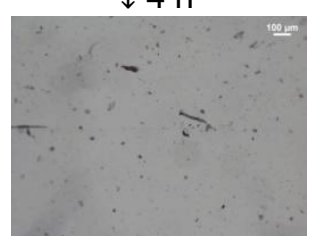




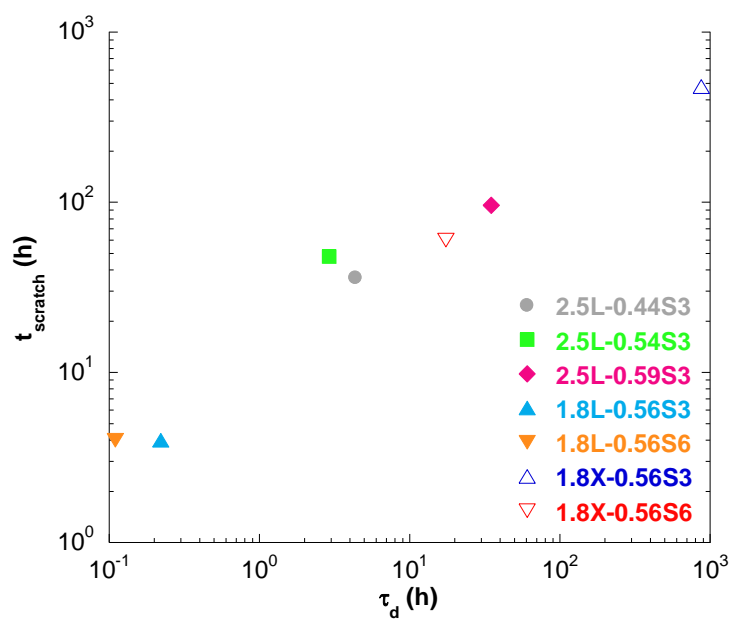

Figure 11. Relationship between the time needed for scratch closure ( $t_{\text {scratch}}$ ) and the relaxation time $\left(\tau_{d}\right)$ at $80^{\circ} \mathrm{C}$ for the linear PUUs and the cross-linked 1.8X-0.56S3 and 1.8X-0.56S6.
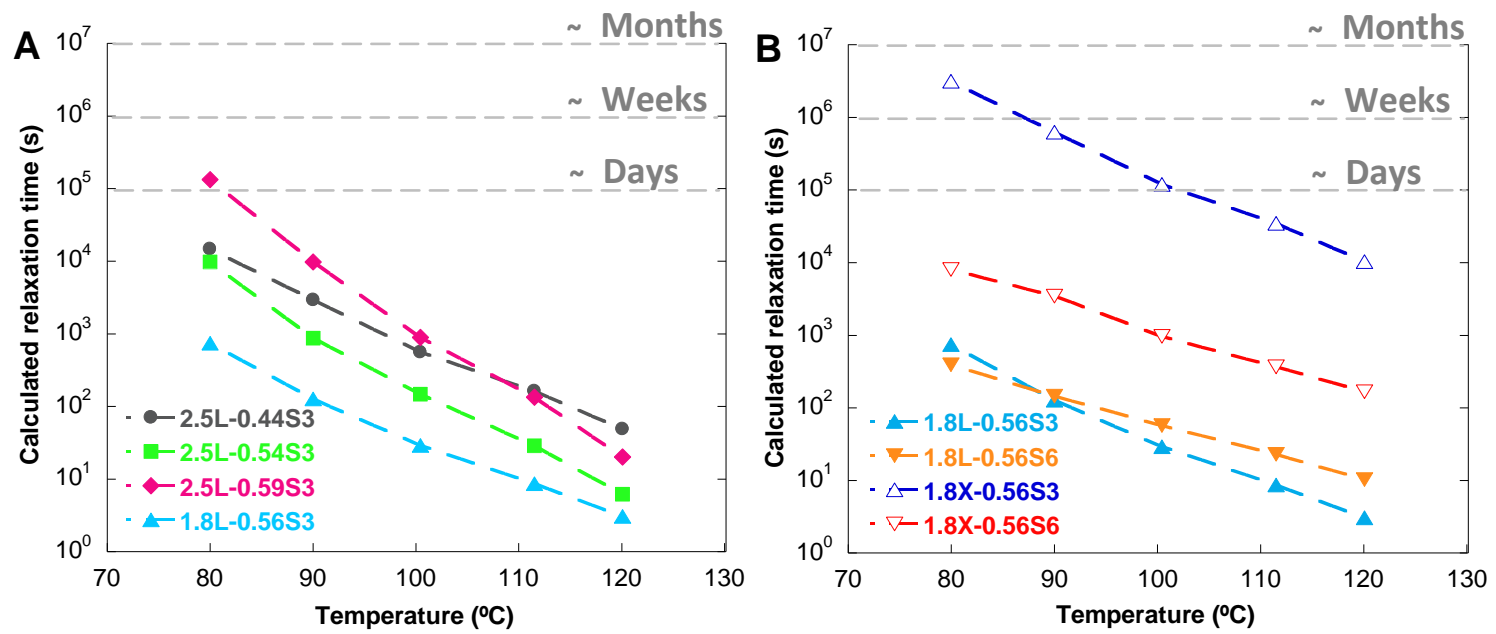

Figure 12. Calculated relaxation times in function of T for the linear PUUs based on S3 (A) and for $1.8 \mathrm{~L} / \mathrm{X}-0.56 \mathrm{~S} 3$ versus $1.8 \mathrm{~L} / \mathrm{X}-0.56 \mathrm{~S} 6(\mathrm{~B})$.

\section{Conclusions}

A series of waterborne PUU dispersions was synthesized so that the effect of the polymer microstructure on the mechanical properties, rheological behaviour and scratch closing ability of the material could be systematically studied. Although incorporation of a sufficiently high amount of the self-healing moiety was necessary to introduce enough mobility into the PUU backbone, higher amounts of aromatic disulfide increased the rigidity to a level that it limited the disulfide exchange. Nevertheless, reducing the amount of chain extender and thus the formation of urea moieties and their associated $\mathrm{H}$-bonds, allowed the incorporation of sufficient disulfide compound, so that materials with significant strength as well as mobility could be obtained since the disulfide exchange is less hindered by physical interactions. Additionally, by changing the chain extender from a difunctional amine (HDA) into a trifunctional amine (DETA), cross-linking points could be introduced into the PUU material which strongly decreased the mobility of the polymer. 
Interestingly, since dynamic disulfide bonds are present in the network, a crossover point could still be observed in the master curves $\left(T_{\text {ref }}=80^{\circ} \mathrm{C}\right)$ obtained by TTS, showing a relaxation time significantly above the levels of those of the linear PUUs. In addition, replacing the disulfide $\mathrm{S}_{2}\left(\mathrm{Ph}\left(\mathrm{CH}_{2}\right)_{3} \mathrm{OH}\right)_{2} \quad$ (S3) by its more flexible alternative $\mathrm{S}_{2}\left(\mathrm{Ph}\left(\mathrm{CH}_{2}\right)_{6} \mathrm{OH}\right)_{2}(\mathrm{~S} 6)$ increased the mobility of the material to an even higher extent, it was feasible to increase the mobility of the material to an even higher extent, so that possibly by incorporating more self-healing agent even stronger and simultaneously more mobile materials could be developed. This proved the fact that varying and optimizing the various building blocks involved in the polymer synthesis can give rise to a polymer architecture which is necessary to obtain self-healing materials which present high mechanical properties with tensile strengths up to roughly 20MPa while showing sufficient mobility at moderate temperatures. Further research will focus on determining if the selfhealing efficiency of these strong materials can be increased above the level of existing systems, so that these waterborne PUU dispersions meet the requirements for potential implementation in coating applications.

\section{Competing interests}

There are no competing interests to declare. Declarations of interest: none.

\section{Data availability}

The raw/processed data required to reproduce these findings cannot be shared at this time as the data also forms part of an ongoing study.

\section{Acknowledgements}

The European Union's Horizon 2020 research and innovation programme is accredited for the financial support through Project TRACKWAY-ITN 642514 under the Marie Sklodowska-Curie grant agreement. N.B. acknowledges the financial support obtained through the Post-Doctoral fellowship Juan de la Cierva - Incorporación (IJCI-2016-28442), from the Ministry of Economy and Competitiveness of Spain.

\section{References}

[1] J. a. Syrett, C.R. Becer, D.M. Haddleton, Polym. Chem. 1 (2010) 978-987.

[2] B.J. Blaiszik, S.L.B. Kramer, S.C. Olugebefola, J.S. Moore, N.R. Sottos, S.R. White, Annu. Rev. Mater. Res. 40 (2010) 179-211.

[3] M. Qiu Zhang, M. Zhi Rong, Self-Healing Polymers and Polymer Composites, Wiley, 2011.

[4] W.H. Binder, Self-Healing Polymers, Wiley-VCH, 2013.

[5] Y. Yang, X. Ding, M.W. Urban, Prog. Polym. Sci. 49-50 (2015).

[6] S. Bode, M. Enke, M. Hernandez, R.K. Bose, A.M. Grande, S. van der Zwaag, U.S. Schubert, S.J. Garcia, M.D. Hager, in: M.D. Hager, S. van der Zwaag, U.S.

Schubert (Eds.), Self-Healing Mater., Springer, 2016, pp. 113-142.

[7] P. Zhang, G. Li, Prog. Polym. Sci. 57 (2016) 32-63.

[8] M.D. Hager, P. Greil, C. Leyens, S. van der Zwaag, U.S. Schubert, Self-Healing 
Materials, Springer, 2016.

[9] J. Dahlke, S. Zechel, M.D. Hager, U.S. Schubert, Adv. Mater. Interfaces 1800051 (2018) 1-14.

[10] B. Willocq, F. Khelifa, J. Brancart, G. Van Assche, P. Dubois, J. Raquez, RSC Adv. 7 (2017) 48047-48053.

[11] J. Van Damme, O. van den Berg, L. Vlaminck, J. Brancart, G. Van Assche, F. Du Prez, Eur. Polym. J. 105 (2018) 412-420.

[12] K. Imato, A. Takahara, H. Otsuka, Macromolecules 48 (2015) 5632-5639.

[13] M. Röttger, T. Domenech, R. van der Weegen, A. Breuillac, R. Nicolaÿ, L. Leibler, Science (80-. ). 356 (2017) 62-65.

[14] X. An, R.H. Aguirresarobe, L. Irusta, F. Ruiperez, J.M. Matxain, X. Pan, N. Aramburu, D. Mecerreyes, H. Sardon, J. Zhu, Polym. Chem. 8 (2017) 3641-3646.

[15] A. Feula, X. Tang, I. Giannakopoulos, A.M. Chippindale, I.W. Hamley, F. Greco, C. Paul Buckley, C.R. Siviour, W. Hayes, Chem. Sci. 7 (2016) 4291-4300.

[16] P. Sun, J. Wang, X. Yao, Y. Peng, X. Tu, P. Du, Z. Zheng, X. Wang, ACS Appl. Mater. Interfaces 6 (2014) 12495-12504.

[17] D.W.R. Balkenende, C.A. Monnier, G.L. Fiore, C. Weder, Nat. Commun. 7 (2016) 10995.

[18] X. Jian, Y. Hu, W. Zhou, L. Xiao, Polym. Adv. Technol. 29 (2018) 463-469.

[19] L. Zhang, L. Chen, S.J. Rowan, Macromol. Chem. Phys. 218 (2017) 1600320.

[20] A. Rekondo, R. Martin, A. Ruiz de Luzuriaga, G. Cabañero, H.J. Grande, I. Odriozola, Mater. Horizons 1 (2014) 237-240.

[21] S. Nevejans, N. Ballard, J.I. Miranda, B. Reck, J.M. Asua, Phys. Chem. Chem. Phys. 18 (2016) 27577-27583.

[22] Y. Xu, D. Chen, Macromol. Chem. Phys. 217 (2016) 1191-1196.

[23] S.-M. Kim, H. Jeon, S.-H. Shin, S.-A. Park, J. Jegal, S.Y. Hwang, D.X. Oh, J. Park, Adv. Mater. 30 (2018) 1705145.

[24] Y. Yang, X. Lu, W. Wang, Mater. Des. 127 (2017) 30-36.

[25] A.M. H. Haberle, W. Temme, R. Bergs, N. Steidl, Use of Aqueous Polyurethane Dispersions in Formulations for Crack Sealing Coating Systems. US20030088045A1., US20030088045A1, 2003.

[26] A. Maier, S. Ingrisch, A. Kern, C. Huber, S. Raspl, W. Hiller, R. Stadler, Coating System for Veneered Wood Based on Polyurethane Dispersions Method for the Production and Use Thereof. US20030162892A1, US20030162892A1, 2000.

[27] D. Schütze, G. Kurek, T. Rische, J. Urban, T. Hassel, Polyurethane-Polyurea Dispersions as Coating Compositions. US6642303B2., US6642303B2, 2003.

[28] T. Rische, H. Casselmann, T. Feller, H. Blum, G. Kurek, Polyurethane-Polyurea Dispersions and Their Use as Coating Compositions. US20070049684A1, US20070049684A1, 2005.

[29] M.C.B. P. H. Markusch, J. W. Rosthauser, Stable, Aqueous Dispersions of Polyurethane-Ureas. US4501852A., US4501852A, 1985.

[30] Y. Xiao, H. Huang, X. Peng, RSC Adv. 7 (2017) 20093-20100.

[31] R.H. Aguirresarobe, L. Martin, N. Aramburu, L. Irusta, M.J. Fernandez-Berridi, Prog. Org. Coatings 99 (2016) 314-321.

[32] R.H. Aguirresarobe, L. Martin, M.J. Fernandez-Berridi, L. Irusta, EXPRESS Polym. Lett. 11 (2017) 266-277.

[33] T. Wan, D. Chen, J. Mater. Sci. 52 (2017) 197-207.

[34] T. Wan, D. Chen, Prog. Org. Coatings 121 (2018) 73-79.

[35] U. Lafont, H. Van Zeijl, S. Van Der Zwaag, ACS Appl. Mater. Interfaces 4 (2012) 6280-6288.

[36] A. Ruiz de Luzuriaga, R. Martin, N. Markaide, A. Rekondo, G. Cabañero, J. 
Rodríguez, I. Odriozola, Mater. Horiz. 3 (2016) 241-247.

[37] A. Erice, A. Ruiz de Luzuriaga, J.M. Matxain, F. Ruipérez, J.M. Asua, H.J. Grande, A. Rekondo, Polymer 145 (2018) 127-136.

[38] L. Zhang, S.J. Rowan, Macromolecules 50 (2017) 5051-5060.

[39] M. AbdolahZadeh, A.C. C. Esteves, S. van der Zwaag, S.J. Garcia, J. Polym. Sci. Part A Polym. Chem. 52 (2014) 1953-1961.

[40] M. Abdolah Zadeh, A.M. Grande, S. van der Zwaag, S.J. Garcia, RSC Adv. 6 (2016) 91806-91814.

[41] N. García-Huete, W. Post, J.M. Laza, J.L. Vilas, L.M. León, S.J. García, Eur. Polym. J. 98 (2018) 154-161.

[42] A.M. Grande, R. Martin, I. Odriozola, S. van der Zwaag, S.J. Garcia, Eur. Polym. J. 97 (2017) 120-128.

[43] T. Ohishi, Y. Iki, K. Imato, Y. Higaki, A. Takahara, H. Otsuka, Chem. Lett. 42 (2013) 1346-1348.

[44] J.D. O. S. Henze, R. Steinberger, R. Krech, N. Pohlmann, C. Beckmann, Isocyanate-Containing Thermoplastic Polyurethane. US20080207846A1. BASF Aktiengesellschaft Patents, Trademarks and Licenses, US20080207846A1, 2008.

[45] S. Hamzehlou, N. Ballard, P. Carretero, M. Paulis, J.M. Asua, Y. Reyes, J.R. Leiza, Polymer 55 (2014) 4801-4811.

[46] S. Mehravar, N. Ballard, A. Agirre, R. Tomovska, J.M. Asua, Eur. Polym. J. 87 (2017) 300-307.

[47] J.Y. Jho, A.F. Yee, Macromolecules 24 (1991) 1905-1913.

[48] L. Delbreilh, A. Bernès, C. Lacabanne, Int. J. Polym. Anal. Charact. 10 (2005) 4156.

[49] J. Richeton, S. Ahzi, K.S. Vecchio, F.C. Jiang, R.R. Adharapurapu, Int. J. Solids Struct. 43 (2006) 2318-2335.

[50] S. Sahin, P. Yayla, Polym. Test. 24 (2005) 613-619.

[51] E.B. Stukalin, L.H. Cai, N.A. Kumar, L. Leibler, M. Rubinstein, Macromolecules 46 (2013) 7525-7541.

[52] S. Hackelbusch, T. Rossow, P. van Assenbergh, S. Seiffert, Macromolecules 46 (2013) 6273-6286.

[53] S. Bode, M. Enke, R.K. Bose, F.H. Schacher, S.J. Garcia, S. van der Zwaag, M.D. Hager, U.S. Schubert, J. Mater. Chem. A 3 (2015) 22145-22153.

[54] S. Seiffert, J. Sprakel, Chem. Soc. Rev. 41 (2012) 909-930.

[55] S. Trinkle, P. Walter, C. Friedrich, Rheol. Acta 41 (2002) 103-113.

[56] J.D. Ferry, Viscoelastic Properties of Polymers, Wiley, 1980.

[57] M. Müller, U. Seidel, R. Stadler, Polymer 36 (1995) 3143-3150.

[58] F.J. Stadler, W. Pyckhout-Hintzen, J.-M. Schumers, C.-A. Fustin, J.-F. Gohy, C. Bailly, Macromolecules 42 (2009) 6181-6192.

[59] K.E. Feldman, M.J. Kade, E.W. Meijer, C.J. Hawker, E.J. Kramer, Macromolecules 42 (2009) 9072-9081.

[60] X. Callies, C. Fonteneau, C. Véchambre, S. Pensec, J.-M. Chenal, L. Chazeau, L. Bouteiller, G. Ducouret, C. Creton, Polymer 69 (2015) 233-240.

[61] A.M. Grande, J.C. Bijleveld, S.J. Garcia, S. van der Zwaag, Polymer 96 (2016) 2634.

[62] R.K. Bose, M. Enke, A.M. Grande, S. Zechel, F.H. Schacher, M.D. Hager, S.J. Garcia, U.S. Schubert, S. van der Zwaag, Eur. Polym. J. 93 (2017) 417-427.

[63] E. Delebecq, J.-P. Pascault, B. Boutevin, F. Ganachaud, Chem. Rev. 113 (2013) 80-118.

[64] S.J. García, H.R. Fischer, S. van der Zwaag, Prog. Org. Coatings 72 (2011) 211221. 
[65] S.J. Garcia, Eur. Polym. J. 53 (2014) 118-125.

[66] R.K. Bose, N. Hohlbein, S.J. Garcia, A.M. Schmidt, S. van der Zwaag, Phys. Chem. Chem. Phys. 17 (2015) 1697-1704. 


\section{Supplementary Information}

Flexible aromatic disulfide monomers for high-performance self-healable linear and cross-linked poly(urethane-urea) coatings

Sil Nevejans, ${ }^{a, b}$ Nicholas Ballard, ${ }^{a}$ Mercedes Fernández, ${ }^{a}$ Bernd Reck, ${ }^{b}$ and José M. Asua ${ }^{a^{\star}}$

${ }^{a}$ POLYMAT, University of the Basque Country UPV/EHU, Joxe Mari Korta Center, Avenida Tolosa 72, 20018

Donostia-San Sebastián, Spain, E-mail: jm.asua@ehu.es

${ }^{b}$ Dispersions and Colloidal Materials, BASF SE, 67056 Ludwigshafen, Germany
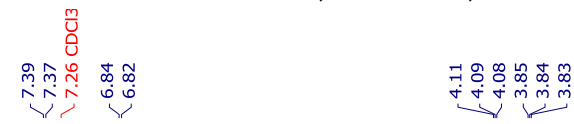

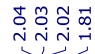
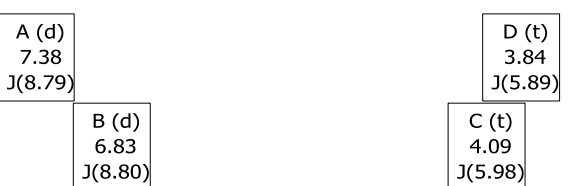

$$
\begin{array}{|c|}
\hline F(s) \\
1.81 \\
\hline E(m) \\
2.03 \\
\hline
\end{array}
$$

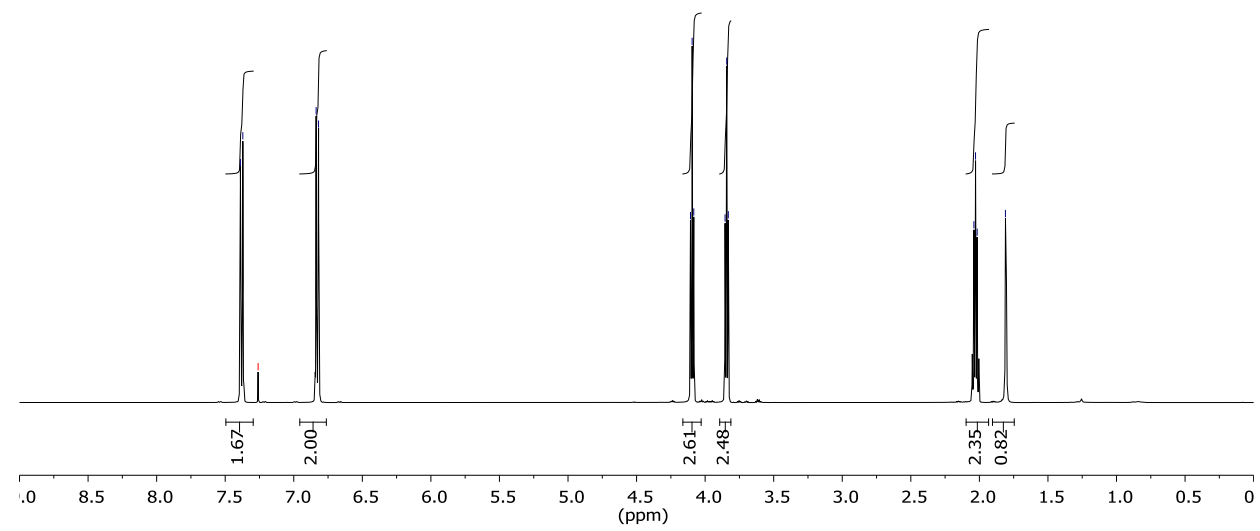

Figure S1. ${ }^{1} \mathrm{H}-\mathrm{NMR}$ of compound bis[4-(3'-hydroxypropoxy)phenyl]disulfide.
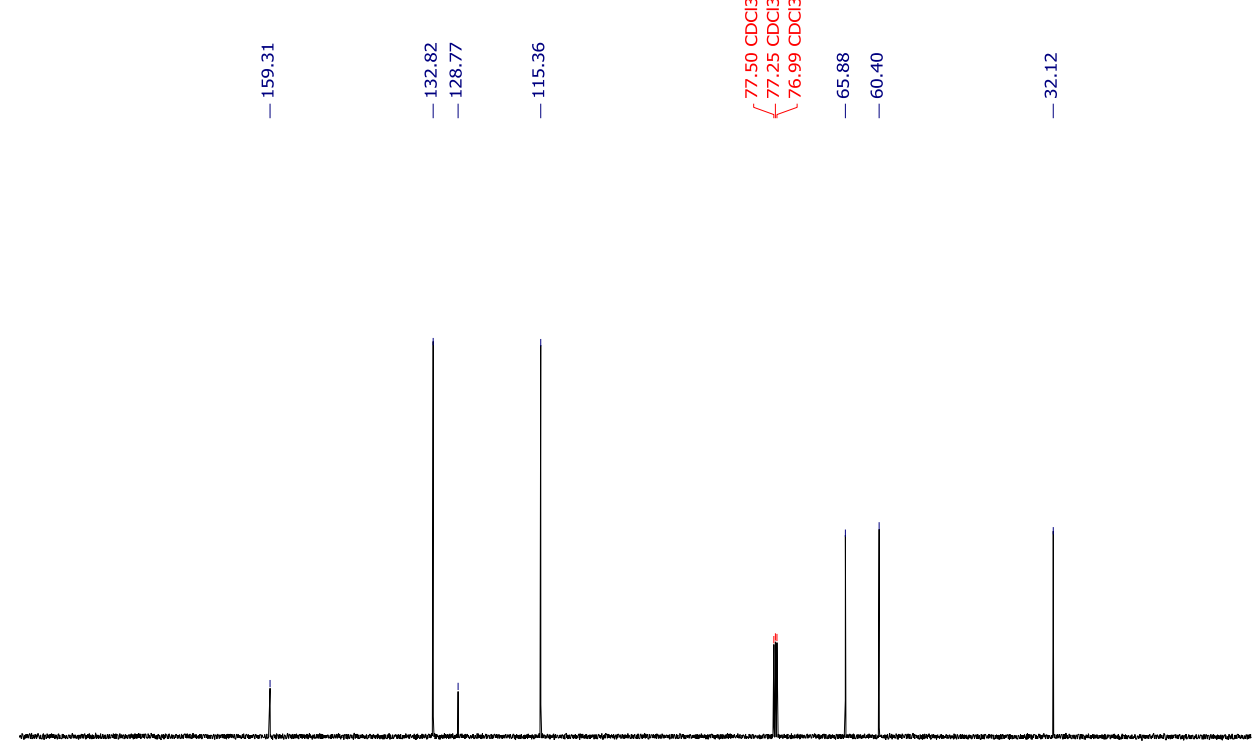

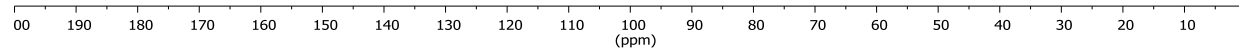

Figure S2. ${ }^{13} \mathrm{C}\{\mathrm{H}\}-\mathrm{NMR}$ of compound bis[4-(3'-hydroxypropoxy)phenyl]disulfide. 


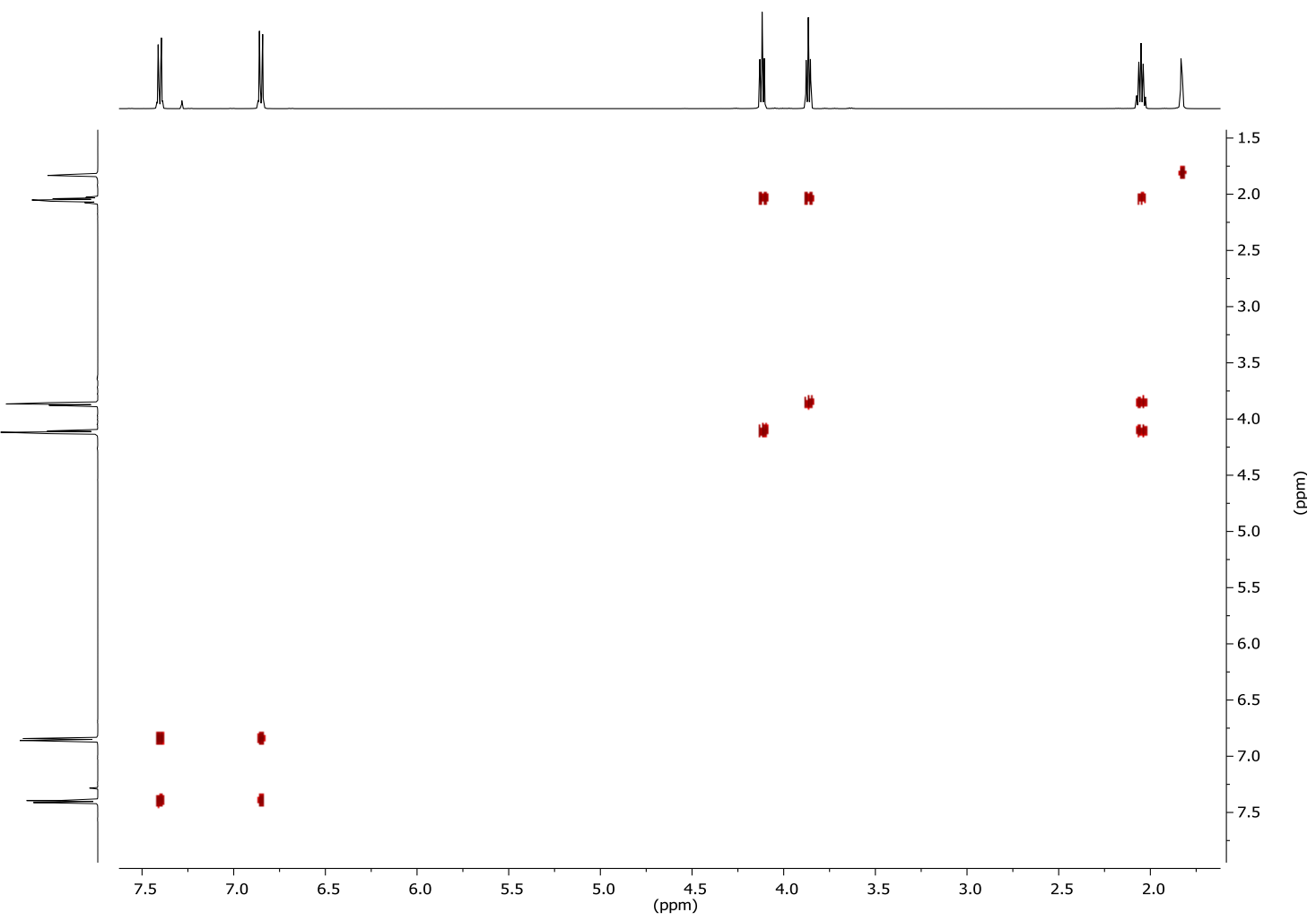

Figure S3. g-COSY (correlation spectroscopy) of compound bis[4-(3'-hydroxypropoxy)phenyl]disulfide.

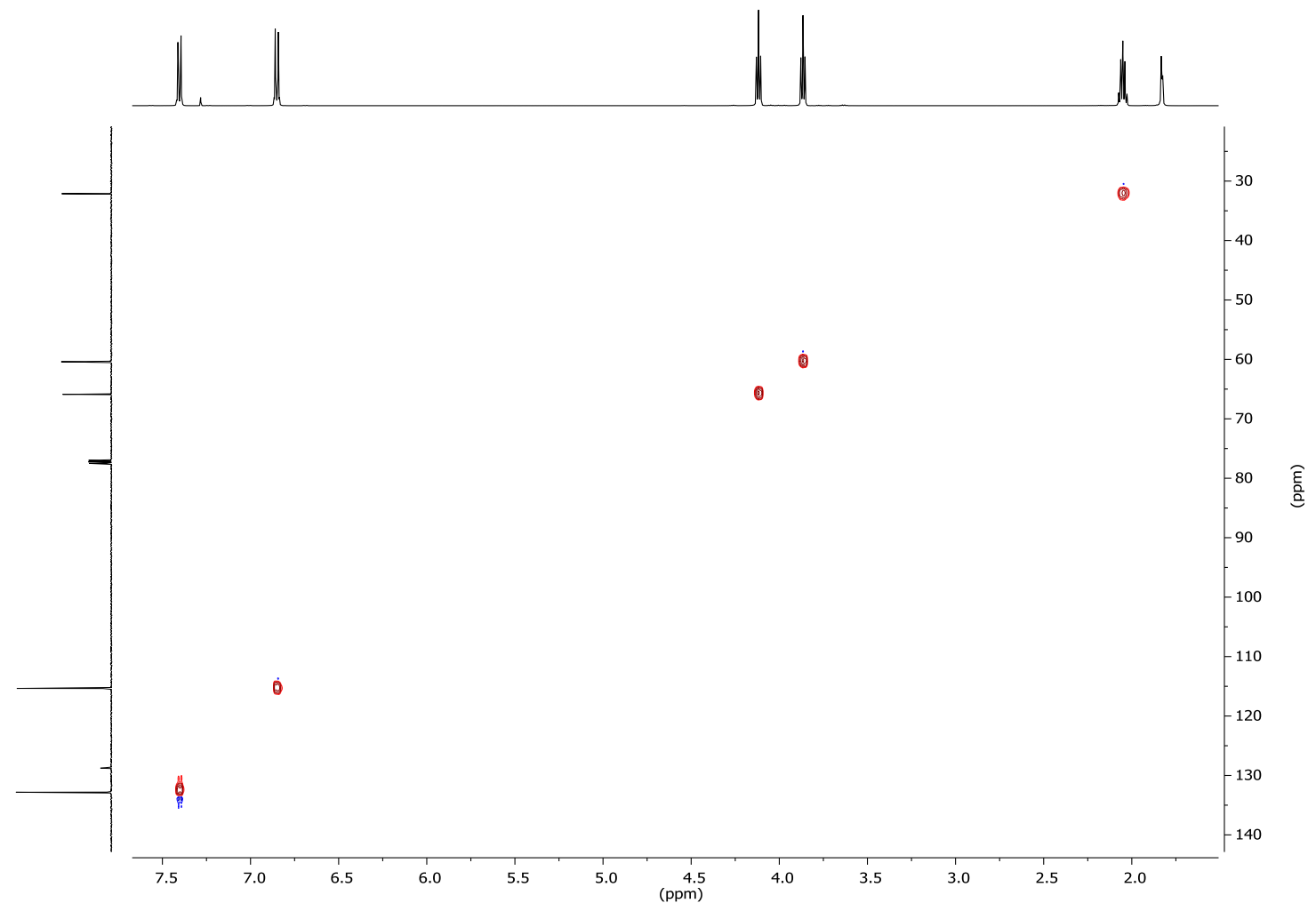

Figure S4. g-HSQC (Heteronuclear Single-Quantum Correlation spectroscopy) of compound bis[4-(3'hydroxypropoxy)phenyl]disulfide. 


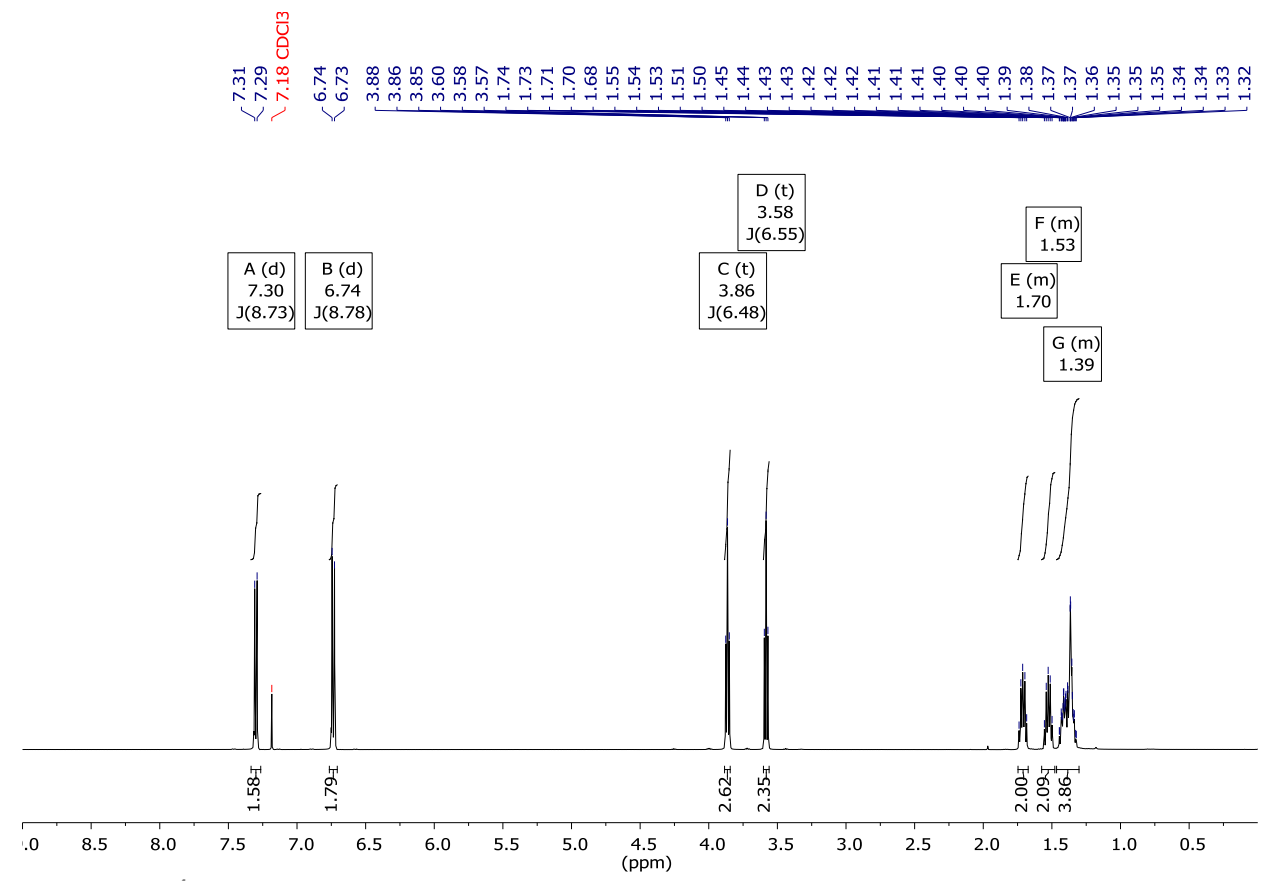

Figure S5. ${ }^{1} \mathrm{H}-\mathrm{NMR}$ of compound bis[4-(6'-hydroxyhexoxy)phenyl]disulfide.

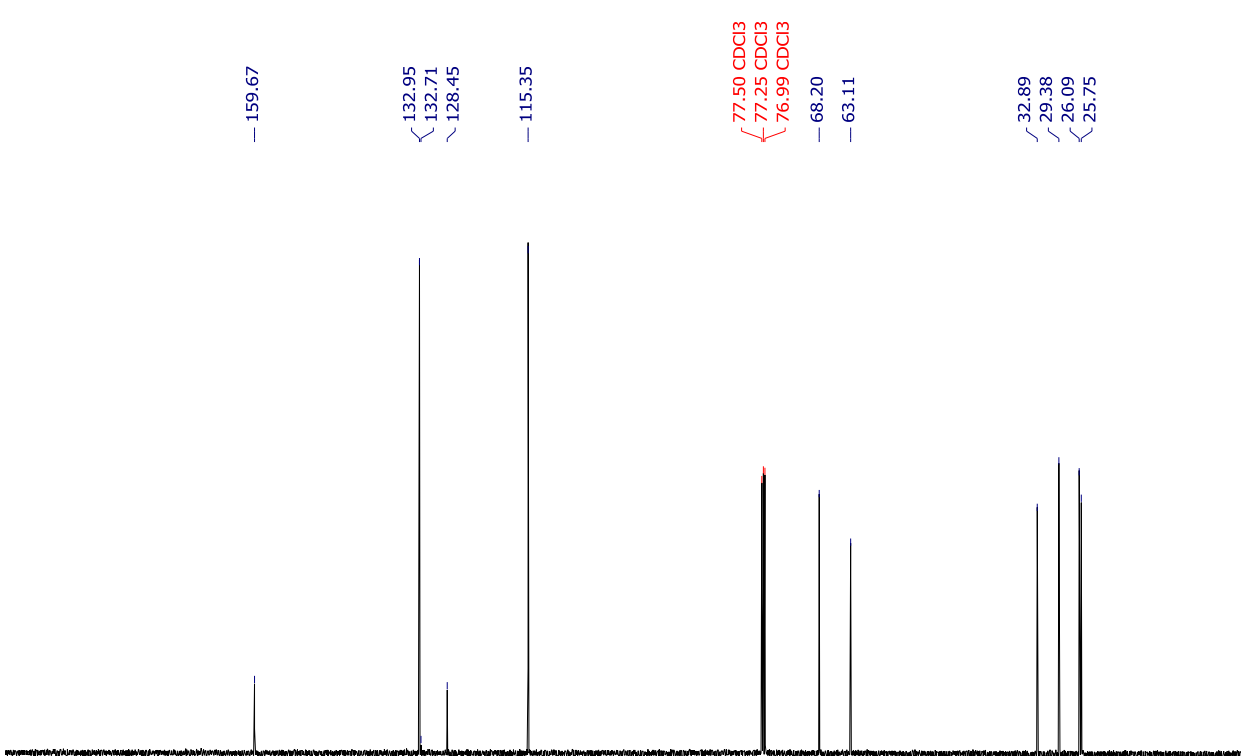

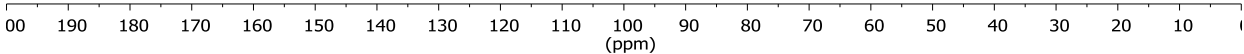

Figure S6. ${ }^{13} \mathrm{C}\{\mathrm{H}\}-\mathrm{NMR}$ of compound bis[4-(6'-hydroxyhexoxy)phenyl]disulfide. 


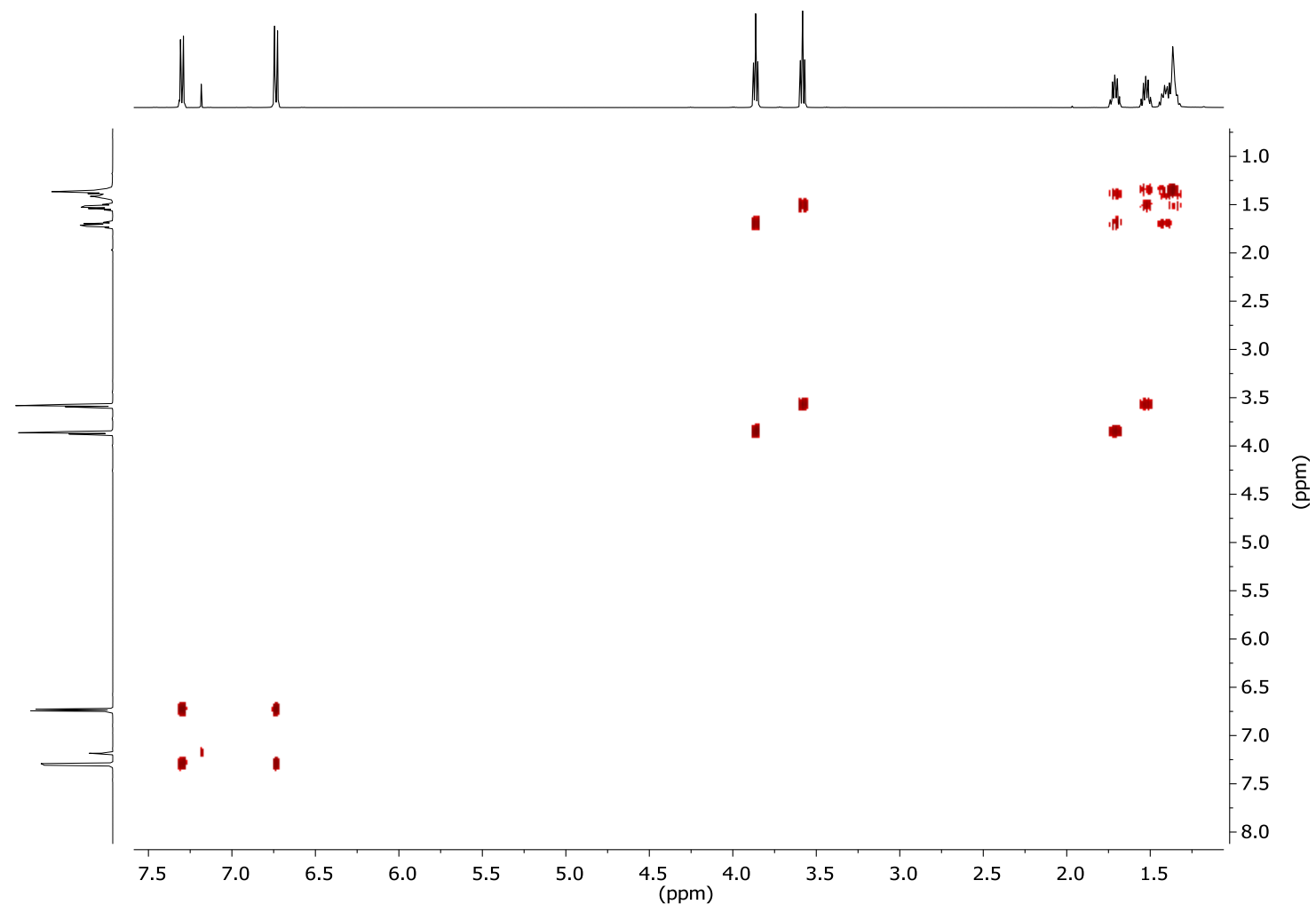

Figure S7. g-COSY of compound bis[4-(6'-hydroxyhexoxy)phenyl]disulfide.

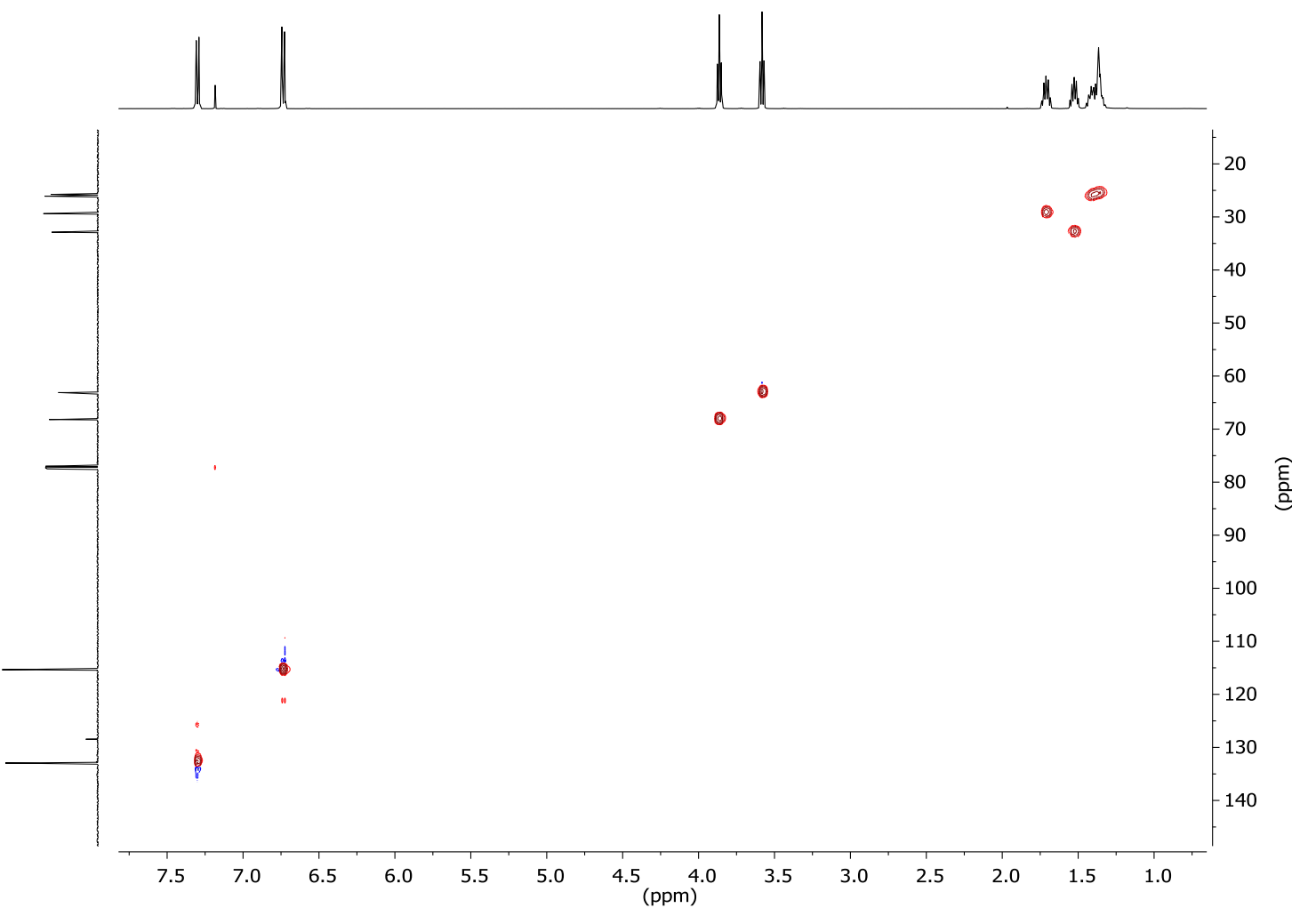

Figure S8. g-HSQC compound bis[4-(6'-hydroxyhexoxy)phenyl]disulfide. 


\section{Linear PUUs}
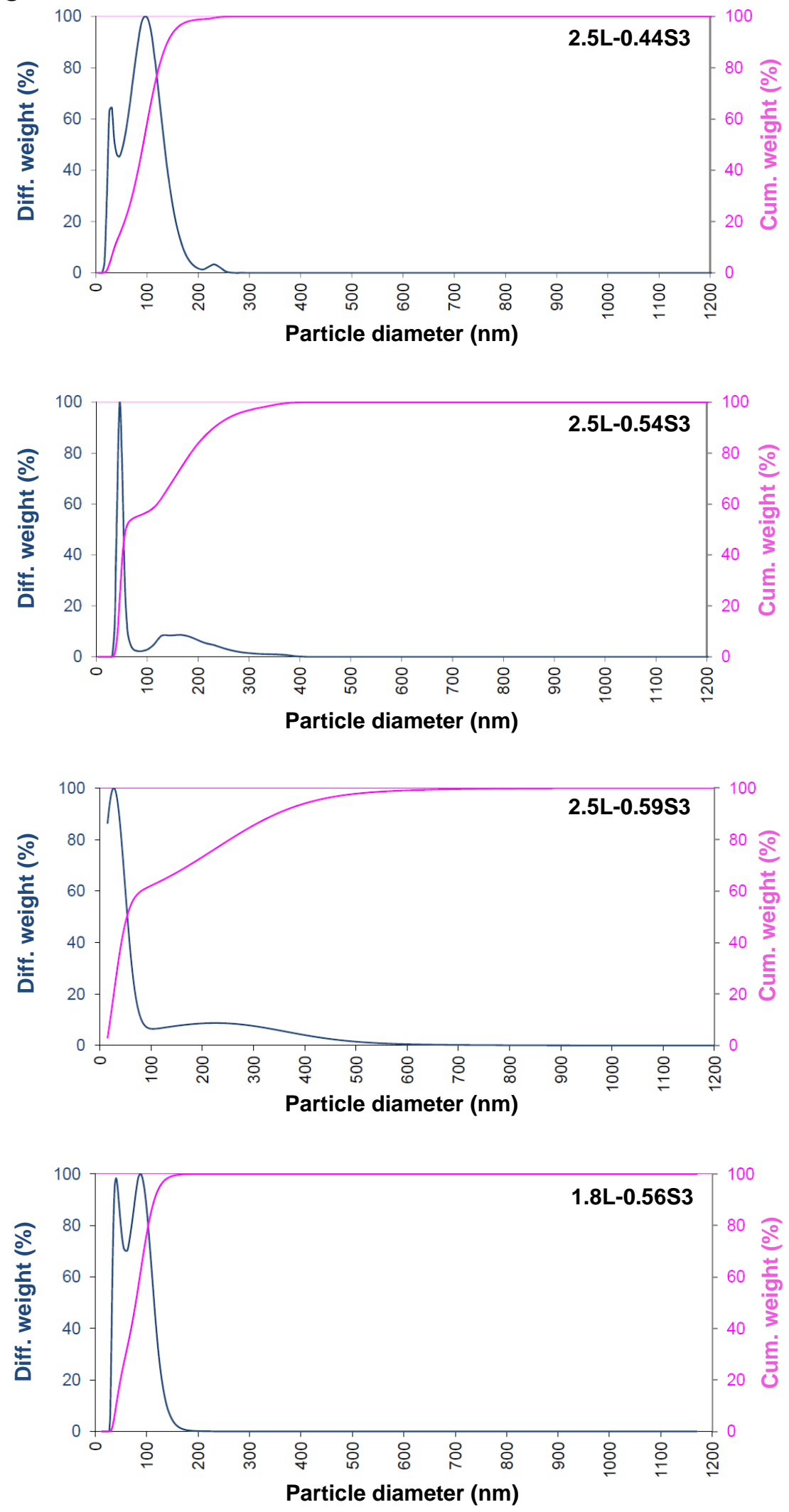


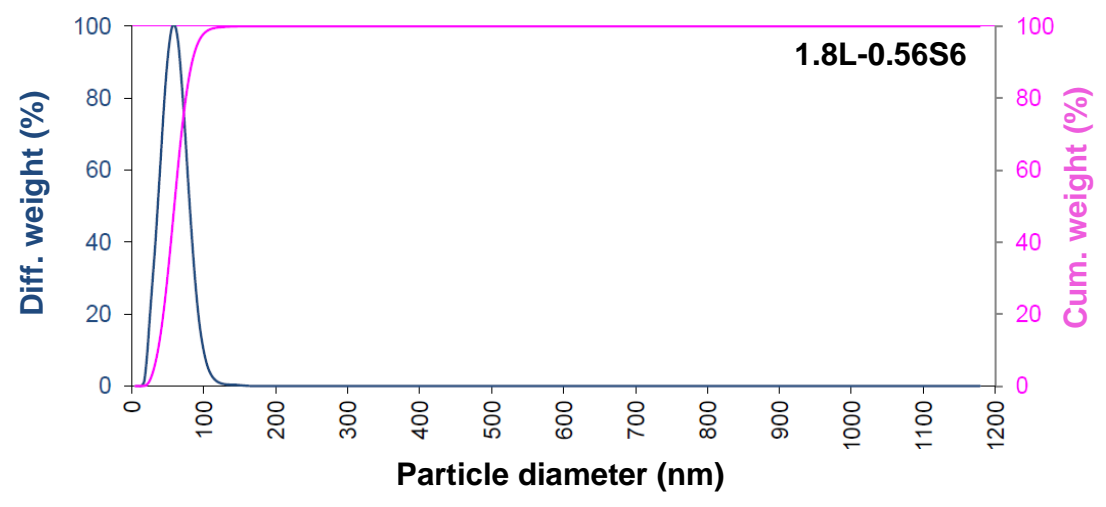

Cross-linked PUUs
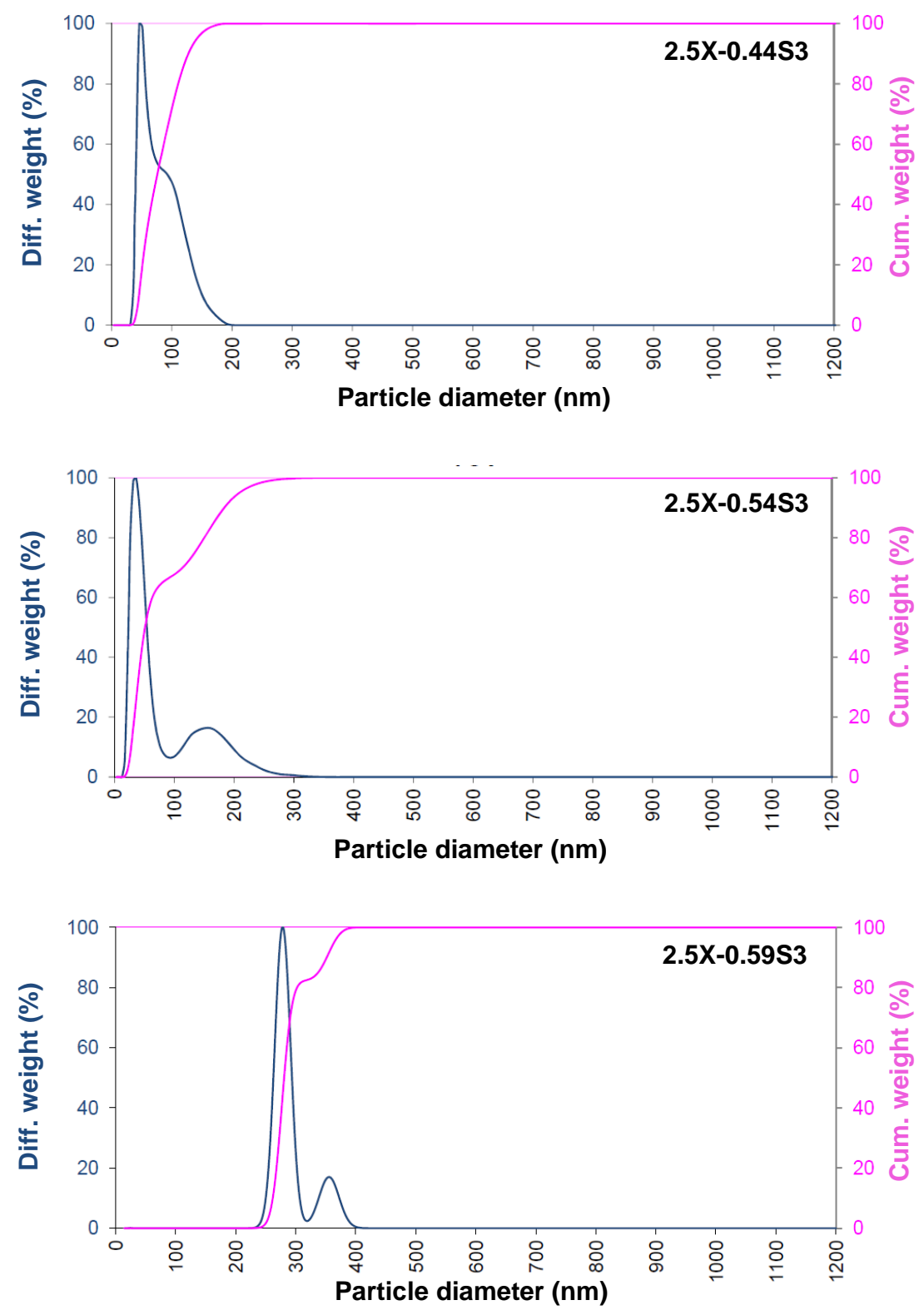

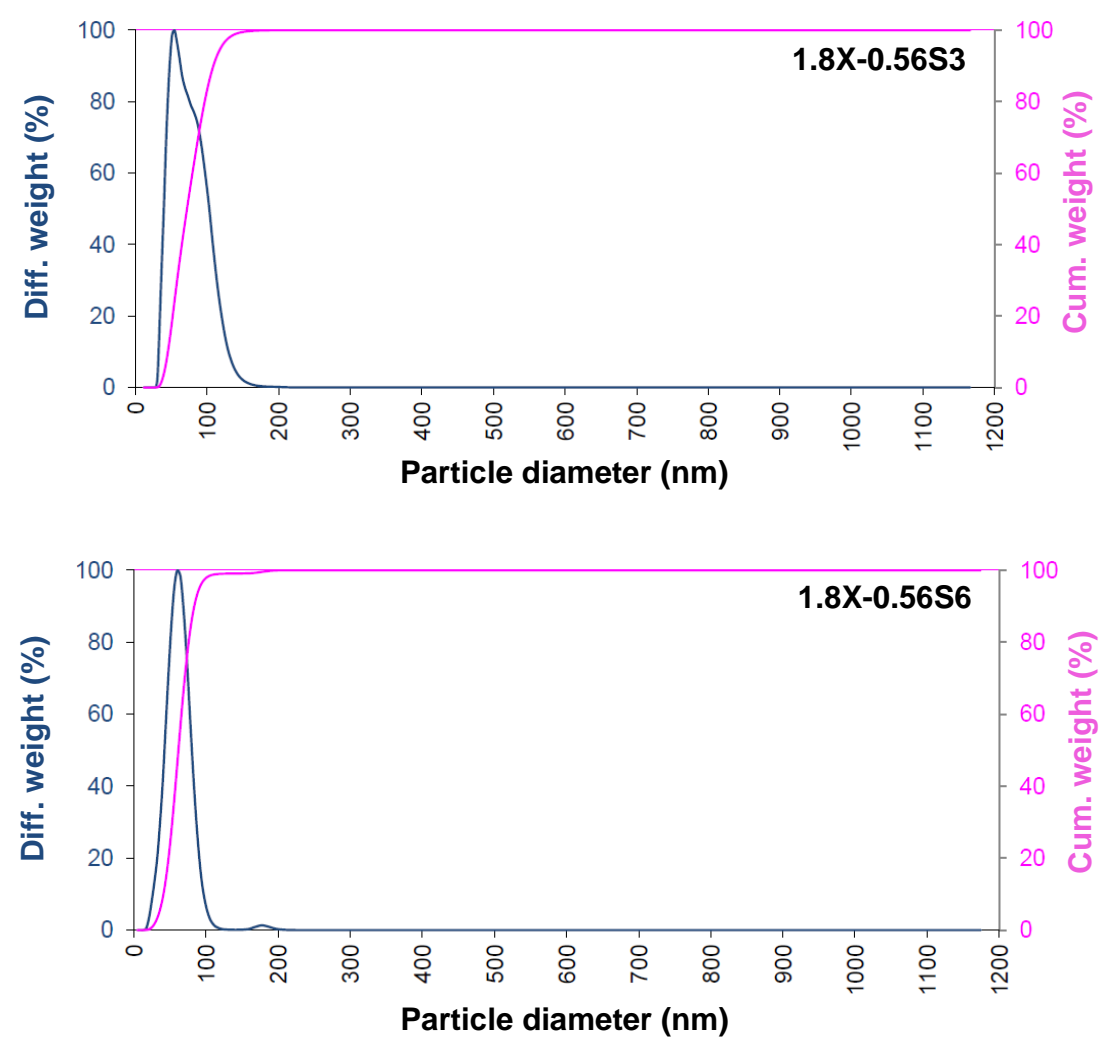

Figure S9. Particle size distribution graphs obtained by HDC for the linear and cross-linked PUUs. 

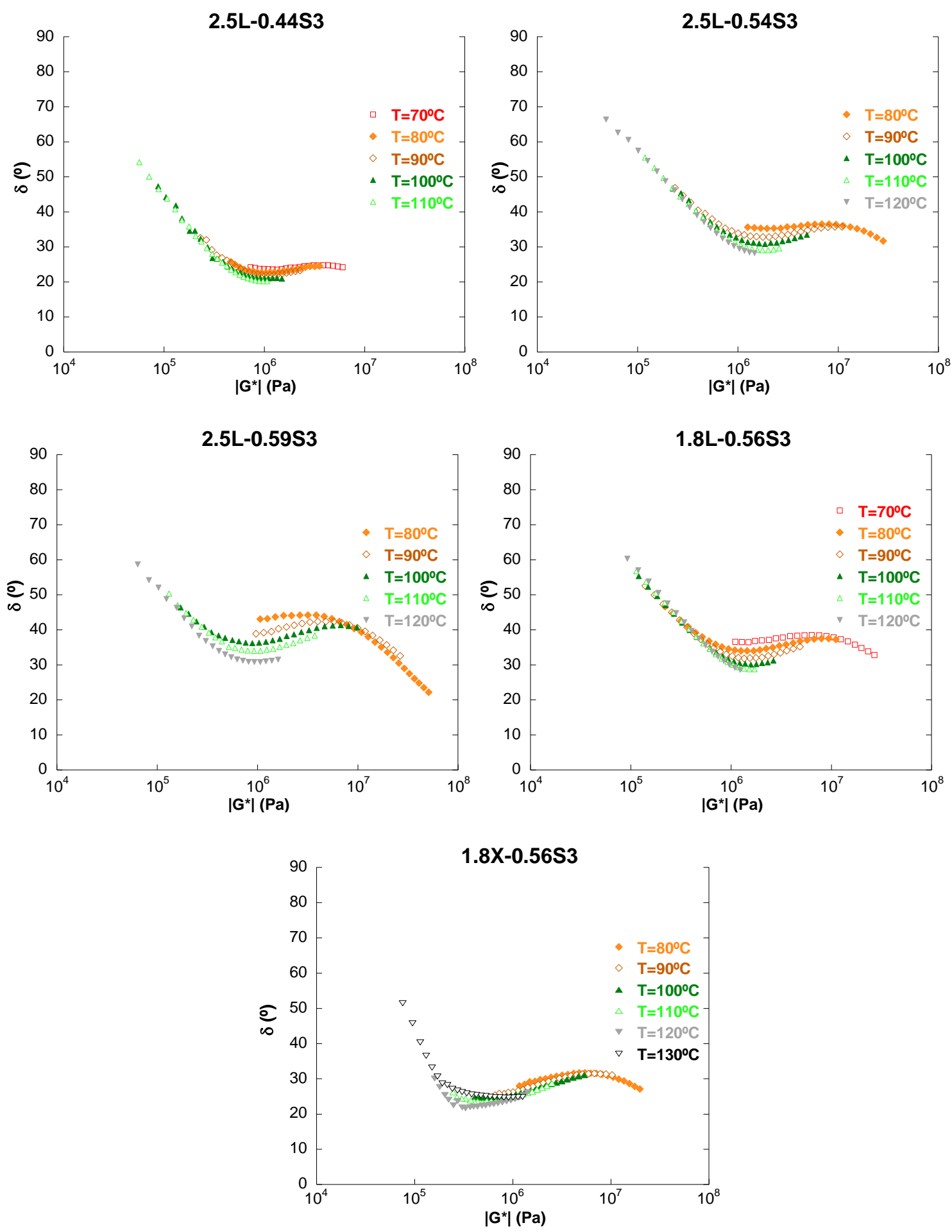

Figure S10. van-Gurp-Palmen-plots of PUUs based on $\mathrm{S}_{2}\left(\mathrm{Ph}\left(\mathrm{CH}_{2}\right)_{3} \mathrm{OH}\right)_{2}(\mathrm{~S} 3)_{\text {. }}$ 

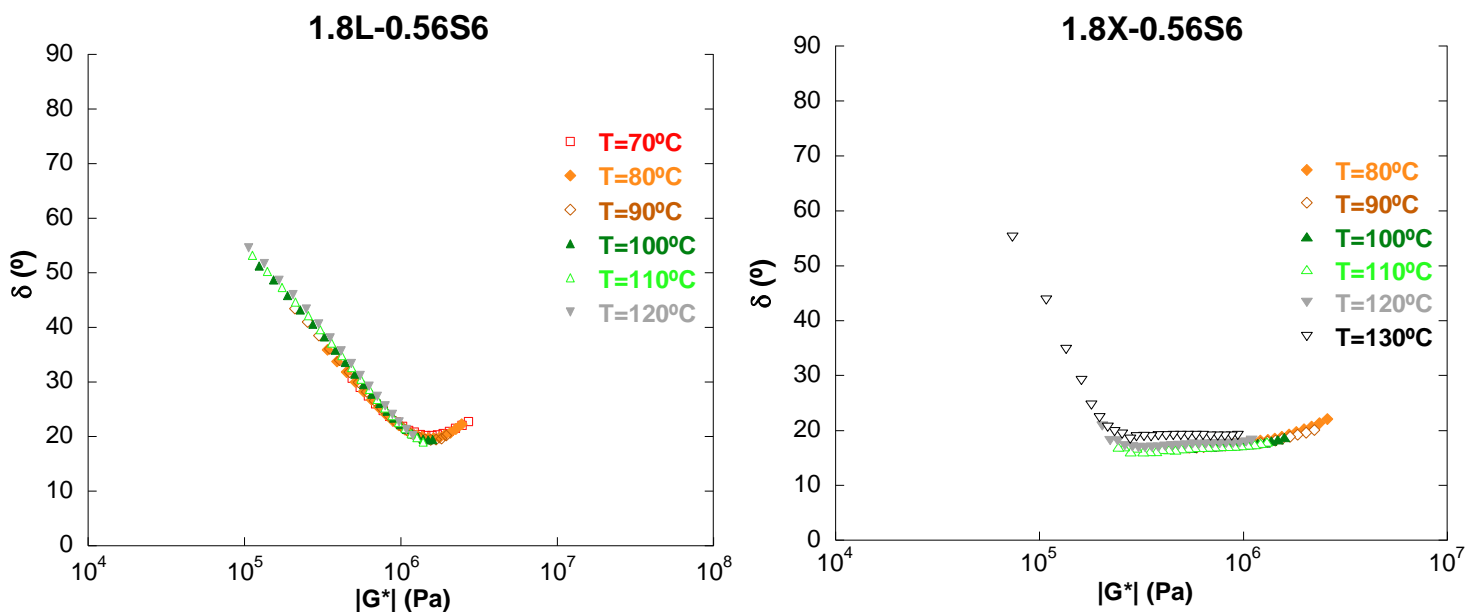

Figure S11. van-Gurp-Palmen-plots of PUUs based on $\mathrm{S}_{2}\left(\mathrm{Ph}\left(\mathrm{CH}_{2}\right)_{6} \mathrm{OH}\right)_{2}(\mathrm{~S} 6)$. 